\title{
The Atmospheric Infrared Sounder version 6 cloud products
}

\author{
B. H. Kahn ${ }^{1}$, F. W. Irion ${ }^{1}$, V. T. Dang ${ }^{1}$, E. M. Manning ${ }^{1}$, S. L. Nasiri ${ }^{2}$, C. M. Naud ${ }^{3}$, J. M. Blaisdell ${ }^{4}$, M. M. Schreier ${ }^{1,5}$,

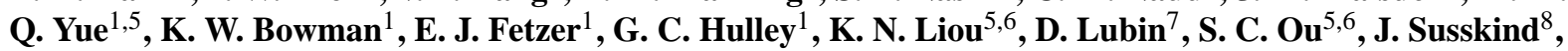 \\ Y. Takano ${ }^{5,6}$, B. Tian $^{1}$, and J. R. Worden ${ }^{1}$ \\ ${ }^{1}$ Jet Propulsion Laboratory, California Institute of Technology, Pasadena, CA, USA \\ ${ }^{2}$ Department of Atmospheric Sciences, Texas A\&M University, College Station, TX, USA \\ ${ }^{3}$ Columbia University, New York, NY, USA \\ ${ }^{4}$ Science Applications International Corporation, NASA Goddard Space Flight Center, Greenbelt, MD, USA \\ ${ }^{5}$ Joint Institute for Regional Earth System Science and Engineering, University of California - Los Angeles, Los Angeles, \\ CA, USA \\ ${ }^{6}$ Department of Atmospheric and Oceanic Sciences, University of California - Los Angeles, Los Angeles, CA, USA \\ ${ }^{7}$ Scripps Institution of Oceanography, University of California - San Diego, La Jolla, CA, USA \\ ${ }^{8}$ NASA Goddard Space Flight Center, Greenbelt, MD, USA
}

Correspondence to: B. H. Kahn (brian.h.kahn@jpl.nasa.gov)

Received: 4 April 2013 - Published in Atmos. Chem. Phys. Discuss.: 3 June 2013

Revised: 26 November 2013 - Accepted: 3 December 2013 - Published: 10 January 2014

\begin{abstract}
The version 6 cloud products of the Atmospheric Infrared Sounder (AIRS) and Advanced Microwave Sounding Unit (AMSU) instrument suite are described. The cloud top temperature, pressure, and height and effective cloud fraction are now reported at the AIRS field-of-view (FOV) resolution. Significant improvements in cloud height assignment over version 5 are shown with FOV-scale comparisons to cloud vertical structure observed by the CloudSat $94 \mathrm{GHz}$ radar and the Cloud-Aerosol LIdar with Orthogonal Polarization (CALIOP). Cloud thermodynamic phase (ice, liquid, and unknown phase), ice cloud effective diameter $\left(D_{\mathrm{e}}\right)$, and ice cloud optical thickness $(\tau)$ are derived using an optimal estimation methodology for AIRS FOVs, and global distributions for 2007 are presented. The largest values of $\tau$ are found in the storm tracks and near convection in the tropics, while $D_{\mathrm{e}}$ is largest on the equatorial side of the midlatitude storm tracks in both hemispheres, and lowest in tropical thin cirrus and the winter polar atmosphere. Over the Maritime Continent the diurnal variability of $\tau$ is significantly larger than for the total cloud fraction, ice cloud frequency, and $D_{\mathrm{e}}$, and is anchored to the island archipelago morphology. Important differences are described between northern and southern hemispheric midlatitude cyclones using storm center composites. The infrared-based cloud retrievals of AIRS provide unique, decadal-scale and global observations of clouds over
\end{abstract}

portions of the diurnal and annual cycles, and capture variability within the mesoscale and synoptic scales at all latitudes.

\section{Introduction}

Clouds remain the largest source of uncertainty in future climate projections (IPCC AR4; see Appendix A for list of acronyms). Several global and multidecadal observational data sets of cloud amount, cloud top height, optical thickness $(\tau)$, effective radius $\left(r_{\mathrm{e}}\right)$, and cloud type are readily available for addressing this source of uncertainty. These include (but are not limited to) the International Satellite Cloud Climatology Project (ISCCP; Rossow and Schiffer, 1999), the High-resolution Infrared Radiation Sounder (HIRS; Wylie et al., 2005), and the Advanced Very High Resolution Radiometer (AVHRR; Heidinger and Pavolonis, 2009; Foster and Heidinger, 2013). Over the last decade, an advanced set of complementary observations of cloud top properties and cloud vertical structure has been obtained with NASA's Atrain constellation of satellites. In particular, the Moderate Resolution Imaging Spectroradiometer (MODIS; Platnick et al., 2003) has provided a wide array of 1 and $5 \mathrm{~km}$ resolution cloud products from both the Terra and Aqua platforms 
since 1999 and 2002, respectively. Furthermore, a much better understanding of the global vertical cloud structure has been obtained from the CloudSat $94 \mathrm{GHz}$ radar (Stephens et al., 2008) and the Cloud-Aerosol LIdar with Orthogonal Polarization (CALIOP; Winker et al., 2010).

Ongoing satellite data set comparisons have revealed that discrepancies among an assortment of publicly available satellite cloud data sets can be explained by differences in instruments, algorithms, and sampling (e.g., Stubenrauch et al., 2013). These multidecadal data sets (and their associated instrument simulators) have been invaluable for processbased evaluations of climate models (Lau and Crane, 1995; Klein and Jakob, 1999; Zhang et al., 2005; Williams and Tselioudis, 2007; Kay et al., 2012; Pincus et al., 2012). However, their utility for long-term, global-scale cloud trends has been uncertain and difficult to determine (Wylie et al., 2005; Evan et al., 2007; Norris and Slingo, 2009). The sign and magnitude of a particular trend may strongly depend on the cloud type, geographical region, and geophysical parameter of interest (Dim et al., 2011; Bender et al., 2012), and satellite sampling characteristics may complicate the assessment of the diurnal cycle (e.g., Foster and Heidinger, 2013). The reasons for discrepancies among satellite estimates of cloud presence, amount, cloud top temperature, and effective emissivity are better understood (e.g., Rossow et al., 1985; Nasiri et al., 2011) than the differences among various estimates of $\tau$, ice cloud effective diameter $\left(D_{\mathrm{e}}\right)$ (Stubenrauch et al., 2013), and cloud thermodynamic phase (Chylek et al., 2006; Nasiri and Kahn, 2008; Hu et al., 2010; Riedi et al., 2010).

Tropical trade cumulus (e.g., Medeiros et al., 2008) and subtropical stratocumulus (e.g., Bony and Dufresne, 2005) are key players in controlling climate sensitivity to radiative forcing. Recent studies have also shown the roles that cloud top height, cloud thermodynamic phase, and ice cloud microphysics play in determining climate sensitivity. Zelinka et al. (2012) showed that the positive longwave cloud feedback due to rising cloud height in the tropics and extratropics outweighs the negative cloud feedback from the reduction in high-cloud amount. Clement et al. (2009) described observational evidence of a reduction in low-cloud amount with increasing SST that leads to a positive shortwave feedback. Other studies find evidence for a negative cloud feedback in the middle and high latitudes, and possibly from an increase in optical depth and/or a transition from ice to liquid phase rather than an increase in cloud amount (Gordon and Norris, 2010; Zelinka et al., 2012). Trenberth and Fasullo (2010) correlated the realism of current-day Coupled Model Intercomparison Project Phase 3 (CMIP3) simulations of Southern Ocean subtropical cloudiness to global estimates of climate sensitivity. This is a region with highly uncertain cloud characterization, including the spatial and temporal morphology of cloud thermodynamic phase.

Recent climate model evaluations highlight an emerging need for additional observational constraints of ice cloud microphysics (Hendricks et al., 2011; Gettelman et al., 2010,
2012) and thermodynamic phase (Tsushima et al., 2006; Cheng et al., 2012), including the complex characteristics of mixed-phase clouds (Storelvmo et al., 2008; Klein et al., 2009). Many contemporary climate models contain explicit representations of ice nucleation, ice supersaturation, and multiple types of cloud and precipitating hydrometeors. An example is the NCAR Community Atmospheric Model (CAM) version 5 (CAM5), which provides more realistic ice water content, cloud frequency, and mixed-phase cloud distributions along with new physical representations of cloud processes. Climate models are sensitive to the formulation of their ice physics (e.g., Barahona et al., 2010; Gettelman et al., 2010; and references therein).

Fasullo and Trenberth (2012) demonstrated that the CMIP Phase 5 (CMIP5) models that contain the lowest subtropical relative humidity $(\mathrm{RH})$ minima are not only the most realistic when compared to AIRS RH but also have the highest climate sensitivities. The connections between climate sensitivity, temperature, and humidity, including their scaledependence and temporal variability, cannot be fully understood independent of cloud morphology (Wood and Field, 2011; Quaas, 2012; Fasullo and Trenberth, 2012). The physical properties of clouds and the larger thermodynamic fields that they are embedded within must be linked at the instantaneous temporal and FOV scales of existing satellite data sets.

Numerous studies have demonstrated that the hyperspectral infrared observations offer greater potential to quantify ice cloud microphysics and cloud thermodynamic phase compared to broadband observations (e.g., Wei et al., 2004; Nasiri and Kahn, 2008; Guignard et al., 2012; Smith et al., 2012; Wang et al., 2013). However, hyperspectral IR cloud retrievals are difficult to calculate because of an excessive computational expense, the complexity and variability of cloud geometry, uncertainties in the underlying surface and atmospheric state, the necessity of using a large set of channels (2378 between 3.7 and $15.4 \mu \mathrm{m}$ in the case of AIRS), and the ongoing difficulty of developing an automated, rigorous, and fast retrieval that is applicable to a $10+\mathrm{yr}$ data record with approximately 2.9 million AIRS FOVs per day. In the work described here, we adopt the optimal estimation retrieval approach of the Tropospheric Emission Spectrometer (TES; Bowman et al., 2006; Kulawik et al., 2006; Eldering et al., 2008) as an a posteriori retrieval algorithm for the ice cloud parameters. This algorithm is computationally rapid and theoretically rigorous, and is further increased in computational efficiency by holding constant all surface and atmospheric parameters except for $\tau, D_{\mathrm{e}}$, and $T_{\mathrm{C}}$ in ice clouds.

This paper describes improvements to existing cloud parameters, and an approach to retrieve new key cloud parameters from the Atmospheric Infrared Sounder (AIRS)/Advanced Microwave Sounding Unit (AMSU; Aumann et al., 2003; Chahine et al., 2006) that ultimately can be used in synergy with the retrieved temperature and specific humidity profiles in atmospheric investigations. The 
Cross-track Infrared Sounder (CrIS) on the Suomi National Polar-orbiting Partnership (Suomi NPP), to be launched on the Joint Polar Satellite System (JPSS), and the Infrared Atmospheric Sounding Interferometer (IASI; Hilton et al., 2012) on EUMETSAT's MetOp satellite will continue the AIRS legacy into the future.

The paper is organized as follows. In Sect. 2, we describe the AIRS level 2 (L2) standard cloud products, improvements made in the version 6 release, and demonstrate improved AIRS cloud top height retrievals when compared against CALIOP and CloudSat cloud top observations matched at the FOV scale. In Sect. 3, the AIRS L2 support cloud products are described including cloud thermodynamic phase and ice cloud $\tau, D_{\mathrm{e}}$, and $T_{\mathrm{C}}$. The method of the ice cloud property retrieval, the logic behind and application of the quality control (QC), and an initial climatology for 2007 are presented and described. In Sect. 4, the AIRS cloud products are used in two separate "stress tests": (1) diurnal variability of ice cloud properties in the Maritime Continent, a region with a large convective diurnal cycle, and (2) composites of summertime Southern Hemisphere ( $\mathrm{SH})$ and wintertime Northern Hemisphere $(\mathrm{NH})$ midlatitude cyclone cloud properties. We discuss and summarize the major findings in Sect. 5 and describe a future outlook in Sect. 6.

\section{The AIRS instrument and cloud top pressure/temperature and effective cloud fraction retrieval}

The AIRS instrument suite was launched on the Aqua satellite in May 2002, and is in a sun-synchronous orbit with an equatorial crossing time of 01:30 and 13:30 local time (LT) in the descending and ascending node, respectively. The spatial resolution of AIRS at nadir view is $13.5 \mathrm{~km}$ and there are approximately 2.9 million FOVs observed in a single day. The temperature and water vapor profiles are obtained in $3 \times 3$ arrays of AIRS FOVs that are coregistered to AMSU in a field of regard (FOR), and up to 324000 retrievals per day are obtained by a cloud-clearing methodology (Susskind et al., 2003, 2006; see Appendix B). Some of the major changes between the operational version 5 (v5) and version 6 (v6) retrieval algorithms are summarized in Olsen et al. (2013). The cloud top height $\left(Z_{\mathrm{C}}\right)$, pressure $\left(P_{\mathrm{C}}\right)$, temperature $\left(T_{\mathrm{C}}\right)$, and effective cloud fraction (ECF) fields are retrieved after completion of the cloud-clearing steps by comparing calculated and observed AIRS radiances in a set of channels sensitive to cloud amount and height (Kahn et al., 2007). The ECF retrieval assumes the cloud emissivity is spectrally flat. The ECF is the product of the cloud fraction and the cloud emissivity, i.e., the value of cloud fraction if the emissivity were always 1.0. For a cloud that is transmissive, the equivalent opaque fraction is reported, as this algorithm cannot distinguish radiation through clouds from radiation around clouds.
For simplicity, and the availability of correlative data sets, the cloud top $T_{\mathrm{C}}$ and $Z_{\mathrm{C}}$ will be presented henceforth.

\subsection{What is new in version 6}

The most significant change between the v5 and v6 cloud retrieval algorithm is that $T_{\mathrm{C}}$ is retrieved within every nominal $13.5 \mathrm{~km}$ diameter AIRS FOV instead of within the entire $45 \mathrm{~km}$ diameter AIRS/AMSU FOR. Version 5 uses a single retrieval with 20 parameters: two layers of $T_{\mathrm{C}}$ for the AIRS/AMSU FOR, and two layers of nine ECF values for each of the nine AIRS FOVs. Version 6 uses nine separate retrievals in the AMSU FOR and four parameters are retrieved for each AIRS FOV: up to two layers each for both $T_{\mathrm{C}}$ and ECF. By retrieving each AIRS FOV individually, better fits between the simulated and observed cloud configurations are obtained. As a result, this adds an additional spatial resolution of a factor of 3 , and a sampling factor of 9 , for $T_{\mathrm{C}}$ and leads to a higher degree of realism, especially for variability within complex cloud scenes and along cloud edges. If only one layer is retrieved, it is reported in the upper cloud layer, regardless of the altitude.

The v6 retrieved $T_{\mathrm{C}}$ and ECF also benefit from other algorithm improvements in the cloud retrieval and elsewhere in the retrieval system. Since we are allowing for two horizontal layers of clouds as seen from above, there is the potential to create a nonexistent cloud layer that in practice only fits noise, compensates for other retrieval errors, or gives an unphysical best-fit solution of $<0$ or $>100 \%$ cloudiness. Our conjecture is that this "noise" in the ECF retrievals arises from the assumption of horizontally uniform surface temperature and emissivity fields, and the assumption of uniform temperature and water vapor profiles in the AIRS/AMSU FOR. Any noncloud horizontal variability may be interpreted as additional structure in the ECF fields. The v6 algorithm better constrains the compensating cloud layer cases by improved logic for deciding when a one-cloud-layer solution adequately matches the radiances, and for converging to a solution away from a shallow minimum where the best-fit solution is unphysical. Another improvement reduces the chance of placing the cloud above an inversion, which could prevent convergence to a solution.

AIRS channels sensitive to low clouds are also sensitive to the surface. Thus, in overcast conditions, the surface temperature and emissivity are difficult to determine. In v5, we addressed this by using a microwave-only (AMSU) solution in about $17 \%$ of cases to determine the clouds. In v6, the land surface emissivity is retrieved starting from a surface climatology derived from the monthly MODIS MYD11C3 emissivity product, and modified to fit the AIRS spectral channels using the MODIS baseline-fit emissivity approach (Seemann et al., 2008). This provides a more reasonable first guess and more stable solution when there is little information available. In v5, shortwave and longwave window channels were used simultaneously to retrieve the surface parameters 
Table 1. Mean v5 (v6) global (land and ocean only, and land+ocean) area-weighted cloud properties for January 2007. Cloud frequency is defined as an AIRS FOV that contains a value of ECF $>0.01$ (the sum of both cloud layers).

\begin{tabular}{lllllll}
\hline & Upper & Lower & Upper & Lower & Total & Cloud \\
& $T_{\mathrm{C}}(\mathrm{K})$ & $T_{\mathrm{C}}(\mathrm{K})$ & ECF & ECF & ECF & Frequency \\
\hline Global & 241.9 & 271.5 & 0.246 & 0.205 & 0.451 & $80.5 \%$ \\
v5 $(v 6)$ & $(243.4)$ & $(266.1)$ & $(0.282)$ & $(0.156)$ & $(0.438)$ & $(80.1 \%)$ \\
\hline Land & 235.9 & 266.7 & 0.210 & 0.198 & 0.408 & $70.8 \%$ \\
v5 $(v 6)$ & $(236.8)$ & $(265.7)$ & $(0.240)$ & $(0.180)$ & $(0.420)$ & $(70.1 \%)$ \\
\hline Ocean & 244.9 & 274.0 & 0.264 & 0.208 & 0.472 & $85.5 \%$ \\
v5 $(v 6)$ & $(246.8)$ & $(266.3)$ & $(0.303)$ & $(0.145)$ & $(0.448)$ & $(85.4 \%)$ \\
\hline
\end{tabular}

( $T_{\mathrm{S}}$ and emissivity) often resulting in unstable solutions in the presence of clouds and highly reflective surface features (Hulley et al., 2009; Hulley and Hook, 2012). However, in v6 only shortwave window channels are used to retrieve surface temperature $\left(T_{\mathrm{s}}\right)$, which results in more accurate determination of spectral emissivity under more difficult cloud conditions (Susskind and Blaisdell, 2008). Furthermore, v6 uses an IR-microwave neural net solution (Blackwell et al., 2008) as the first guess for temperature and water vapor profiles and $T_{\mathrm{s}}$, which allows for reasonable solutions for many more cases than in v5. In the most overcast conditions over ocean (about $7 \%$ of cases), v6 uses the neural net surface temperature directly when calculating clouds, resulting in a much better depiction of low clouds.

Cloud retrievals for a single AIRS granule in the subtropical western Pacific Ocean region on 6 September 2002 are shown in Fig. 1. This scene was selected as a representative example because of the very large mix of cloud types and weather regimes found within it. The major weather features include tropical cyclone Sinlaku at the western edge, and a frontal system to Sinlaku's north that separates a region of broken and shallow cumulus, thin cirrus, and multilayered cloud structures to the south, and more uniform stratocumulus-type layers in the north. The benefits of the single-FOV v6 cloud retrievals are apparent in the $T_{\mathrm{C}}$ structure, especially along the edges of the frontal system and tropical cyclone, and within the cloud cover to the south of the frontal system. The frequency of FOVs containing twolayered clouds is significantly reduced in v6 compared to v5 (not shown), indicating an improvement in v6 by reducing the frequency of compensating cloud layer cases. A few FOVs within the outer rain bands of Sinlaku contain unrealistically warm $T_{\mathrm{C}}$ and low ECF, but the eye is much sharper than in $\mathrm{v} 5$ and has a more realistic diameter.

The global mean properties of $T_{\mathrm{C}}$, ECF, and cloud frequency are summarized in Table 1. At the AIRS FOV scale, about $80 \%$ of the area of the globe at any given time contains cloud with ECF $>0.01$, and this value is about $70 \%$ over land and $85 \%$ over ocean. Most of the cloud amount is contained in the upper layer, and ocean FOVs contain more than twice the ECF in the upper layer (0.303) compared to the lower layer (0.145). The differences between v5 and v6 are relatively minor except for the increase (decrease) of ECF in the upper (lower) layer in v6, and a compensating change of a few $\mathrm{K}$ in $T_{\mathrm{C}}$. The radiative consistency (Nasiri et al., 2011) of the cloud and surface products is nearly identical between v5 and v6 (not shown) and further implies the presence of compensating (and improved) changes in the ECF and $T_{\mathrm{C}}$ fields.

Global distributions for both layers of $T_{\mathrm{C}}$ and ECF are shown for 2007 in Fig. 2. The tropical convective regions that contain cold cirrus are clearly depicted. The upper layer of $T_{\mathrm{C}}$ in the subtropical stratocumulus regions is significantly warmer than in v5 and indicates a substantial improvement in height assignment (to be quantified below). Furthermore, the lower layer of $T_{\mathrm{C}}$ is warmer in the low latitudes and suggests that improvements in v6 could lead to more realistic multilayered cloud configurations. This topic warrants further investigation. The majority of the cloud amount is contained within the upper layer as shown by the magnitudes of ECF. Interestingly, the lower layer of ECF is proportionally higher within tropical convection over South America, central Africa and the Intertropical Convergence Zone (ITCZ) compared to the Maritime Continent. Significant values for the lower layer ECF are also found in the storm tracks that are associated with nimbostratus clouds. This phenomenon also occurs in v5 and is a result of the tenuous nature of the upper portions of nimbostratus clouds and the tendency of the cloud retrieval algorithm to fit a second layer with a large value of ECF well within the cloud layer (Kahn et al., 2008a).

\subsection{AIRS, CloudSat, and CALIOP cloud top height histograms}

Figure 3 shows histograms of AIRS $Z_{\mathrm{C}}$ over global oceans for v5 and v6 compared to cloud tops obtained from the CloudSat $94 \mathrm{GHz}$ radar (Stephens et al., 2008) and the Cloud-Aerosol LIdar with Orthogonal Polarization (CALIOP; Winker et al., 2010) instruments for both single and two-layered clouds. The CloudSat cloud tops are taken from the release 4 (R04) $2 B$-GEOPROF product, 

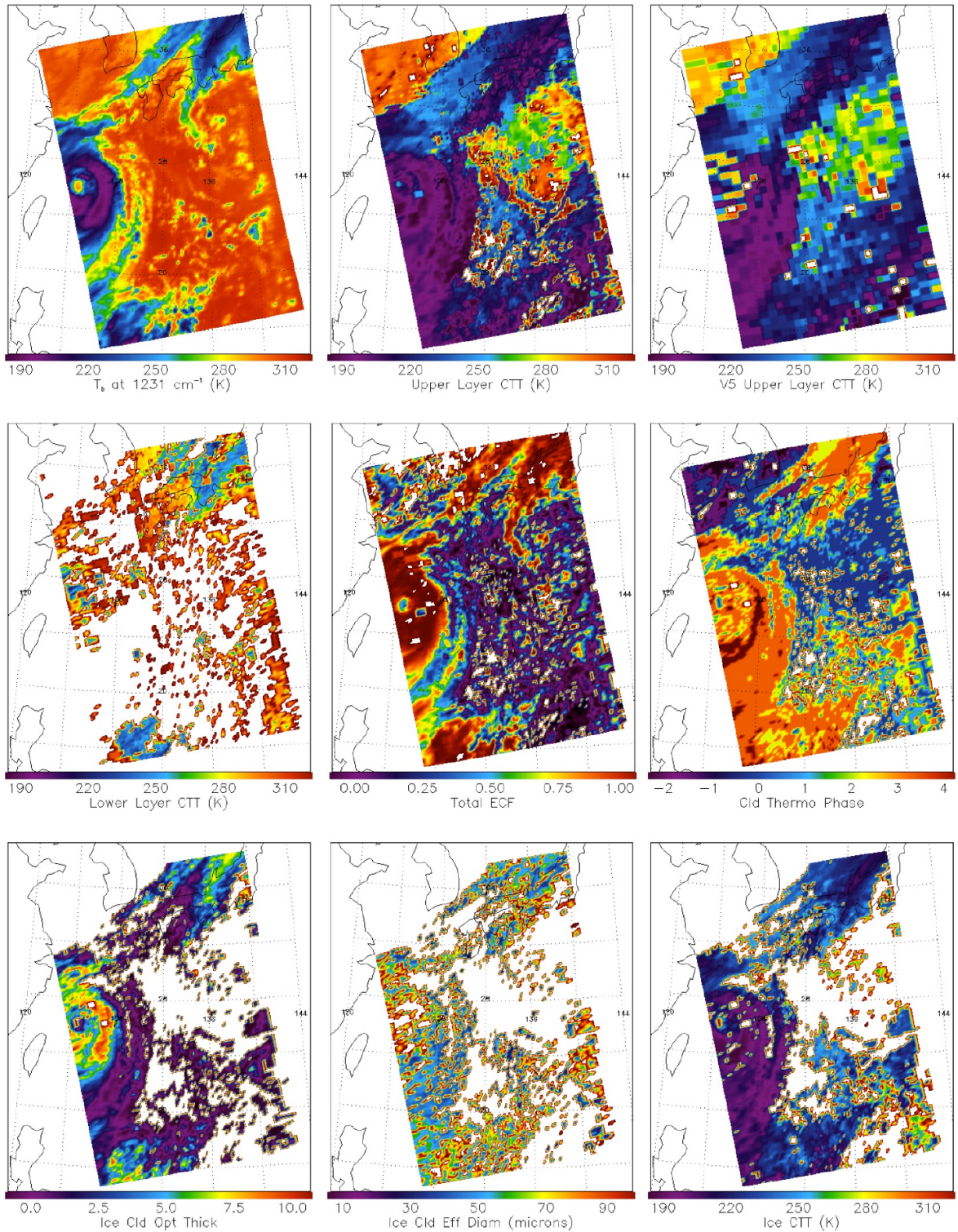

Fig. 1. Granule maps from 6 September 2002. Upper row (left to right) is the $T_{\mathrm{b}, 1231}(\mathrm{~K})$, the v6 upper-layer $T_{\mathrm{C}}$, and the v5 upper-layer $T_{\mathrm{C}}$. Middle row (left to right) is the v6 lower-layer $T_{\mathrm{C}}$, the v6 total ECF, and the v6 cloud thermodynamic phase. Lower row (left to right) is the ice cloud optical thickness $\tau$, ice cloud effective diameter $D_{\mathrm{e}}(\mu \mathrm{m})$, and ice cloud top temperature $T_{\mathrm{C}, \mathrm{ICE}}(\mathrm{K})$. The granule number is 044 with a start (end) time of 04:23:26 (04:29:26) UTC.

and the CALIOP cloud top from the $5 \mathrm{~km}$ feature mask CAL_LID_L2_05kmCLay-Prov-V3-01. The peaks in lowcloud top frequency observed by CloudSat and CALIOP are similar and at about $1.0-1.5 \mathrm{~km}$, with some slight diurnal variability. In the AIRS single-layered retrievals (restricted to clouds with ECF $>0.01$ ), a broad peak in v5 is located at $2-5 \mathrm{~km}$, and in v6 lowers to $1.5-3.5 \mathrm{~km}$. In the AIRS v5 two-layered retrievals, the peak is located even higher than in the single-layered retrievals. However, in $v 6$, the location of the peak is very similar between single- and two-layered retrievals. The diurnal differences in AIRS are minor for this subset of retrievals, although a slightly higher (lower) frequency of two-layered clouds are observed at night (day) in v6. There is a more prominent peak near the tropical tropopause in v6 if all values of ECF are included (not shown). Thus, by filtering out clouds with $\mathrm{ECF}<0.01$, a much more realistic vertical distribution is obtained. CALIOP detects much more frequent tropical thin cirrus, although with a much wider peak than AIRS, and even more at night because of increased signal-to-noise ratio in CALIOP (Sassen et al., 2008; Winker et al., 2010). A small peak near $8 \mathrm{~km}$ in the single-layered $\mathrm{v} 6$ case and a broad peak from 6 to $10 \mathrm{~km}$ in the two-layered $\mathrm{v} 6$ clouds are 

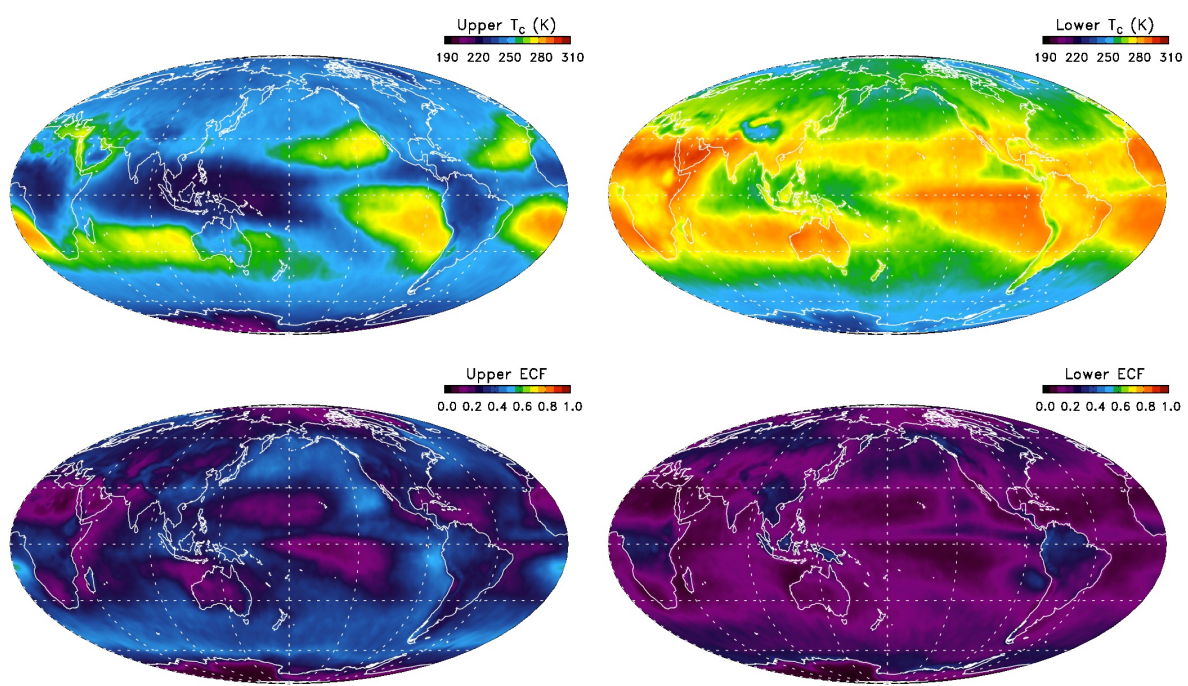

Fig. 2. The AIRS standard L2 cloud top temperature $T_{\mathrm{C}}$ (upper row) and effective cloud fraction ECF (lower row) for the upper layer (left column) and lower layer (right column) for 2007.
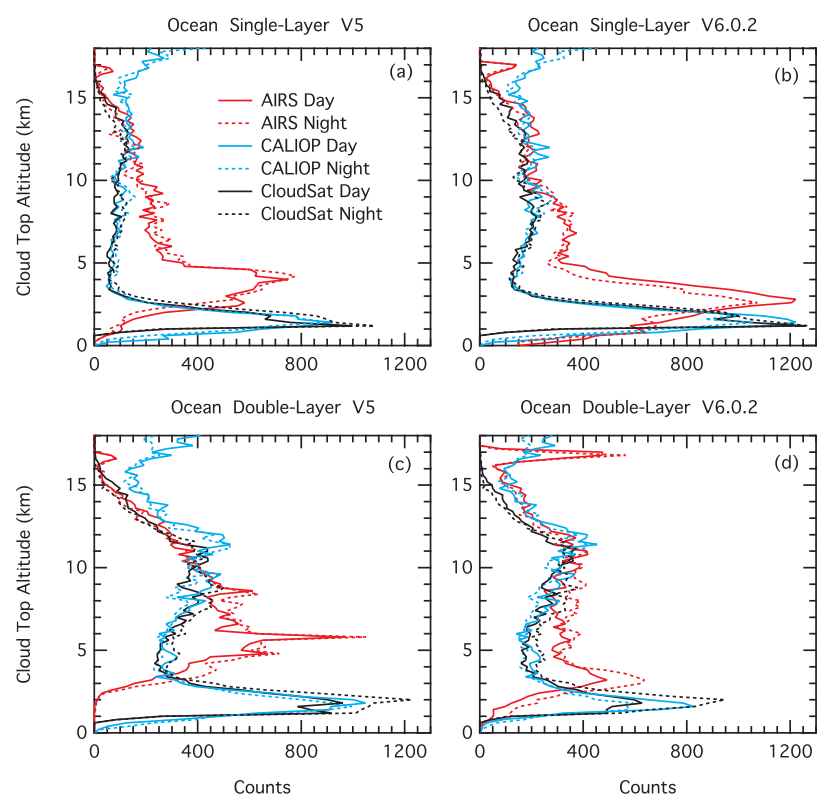

Fig. 3. Cloud top height $Z_{\mathrm{C}}$ frequency for AIRS v5 (left column) and v6 (right column) over the ocean for single-layered cases (upper row) and two-layered cases (lower row) for a one-week period in January 2007. The CloudSat and CALIOP collocated $Z_{\mathrm{C}}$ is also shown on each panel. The CloudSat and CALIOP observations are very similar, but not exactly equal to each other, between the different panels because of slight changes in the AIRS cloud detection between $\mathrm{v} 5$ and $\mathrm{v} 6$.

seen in Fig. 3, and both are largely consistent with the active sensors.

Figure 4 is similar to Fig. 3 except that the global land results are shown (only AIRS clouds with a two-layer
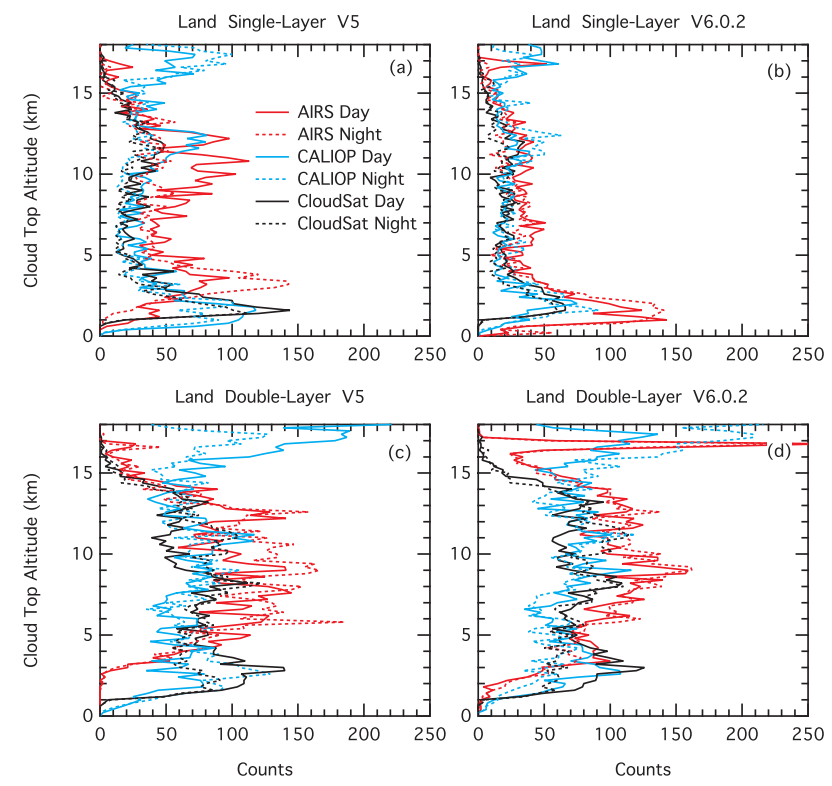

Fig. 4. Same as Fig. 3, except for land.

ECF $>0.01$ are included). Improvement for the low clouds over land is even greater than over the ocean. However, a sharp peak in high thin cloud is observed near $17 \mathrm{~km}$ unlike the ocean cases. An improvement in the realism of the broad peaks near $8-12 \mathrm{~km}$ is observed in $\mathrm{v} 6$ and is more consistent with the active sensors. In summary, the AIRS v6 cloud top height distributions are significantly improved over v5, although AIRS still struggles with locating the height of the thinnest cloud near the tropopause. 


\section{AIRS cloud thermodynamic phase and ice cloud property retrievals}

A new set of cloud products are added to the v6 support product files: these include cloud thermodynamic phase, ice cloud optical thickness $(\tau)$, ice cloud effective diameter $\left(D_{\mathrm{e}}\right)$, and ice cloud top temperature $\left(T_{\mathrm{C}, \mathrm{ICE}}\right)$. Jin (2012) and Jin and Nasiri (2013) describe the cloud thermodynamic phase algorithm, the theoretical basis for the channel selection, and the comparison of cloud thermodynamic phase between AIRS and CALIOP. The radiative transfer simulations of the ice cloud $T_{\mathrm{b}}$ spectra using the delta-four-stream (D4S) radiative transfer model (Yue and Liou, 2009) are described in Ou et al. (2013), while the optimal estimation retrieval approach is adapted from Bowman et al. (2006).

\subsection{Cloud thermodynamic phase}

The cloud thermodynamic phase is based on a series of $T_{\mathrm{b}}$ thresholds and $\Delta T_{\mathrm{b}}$ tests that distinguish the spectral signatures of liquid and ice clouds (Nasiri and Kahn, 2008; Jin, 2012; Jin and Nasiri, 2013). These tests are applied to AIRS FOVs with a total two-layer ECF $>0.01$. A brief description of the key elements of the algorithm follows. There are four different ice-phase tests used: (1) $T_{\mathrm{b}}$ at $960 \mathrm{~cm}^{-1}\left(T_{\mathrm{b}, 960}\right)<235 \mathrm{~K}$, which tests for the presence of optically thick and cold cirrus; (2) the $T_{\mathrm{b}}$ difference between 1231 and $960 \mathrm{~cm}^{-1}\left(\Delta T_{\mathrm{b}, 1231-960}\right)>0.0 \mathrm{~K}$; (3) the $T_{\mathrm{b}}$ difference between 1231 and $930 \mathrm{~cm}^{-1}\left(\Delta T_{\mathrm{b}, 1231-960)}>1.75 \mathrm{~K}\right.$; and (4) the $T_{\mathrm{b}}$ difference between 1227 and $960 \mathrm{~cm}^{-1}$ $\left(\Delta T_{\mathrm{b}, 1231-960}\right)>-0.5 \mathrm{~K}$. Generally speaking, the colder and convective types of ice clouds pass more tests, and thin cirrus passes fewer tests (discussed later). Although detection of ice within the AIRS FOV is the main purpose of the algorithm, there are two different liquid-phase tests: (1) the $T_{\mathrm{b}}$ difference between 1231 and $960 \mathrm{~cm}^{-1}\left(\Delta T_{\mathrm{b}, 1231-960)<-1.0}\right.$ $\mathrm{K}$, and (2) the $T_{\mathrm{b}}$ difference between 1231 and $930 \mathrm{~cm}^{-1}$

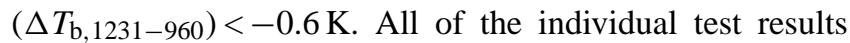
are reported in the field cloud_phase_bits. Similar to the ice cloud cases, the uniform and homogeneous liquid clouds more often pass both tests than do broken clouds. In the case of "unknown" cloud, Jin and Nasiri (2013) show that over $99 \%$ of these cases pass no ice or liquid tests (less than $1 \%$ have at least one liquid and ice test each simultaneously passing). After summing the results of all tests, "ice" is obtained if the value is positive (between +1 and +4 ) and "liquid" if negative (either -1 or -2 ). These values are reported in the field cloud_phase_3× 3 .

The granule map of cloud thermodynamic phase in Fig. 1 shows numerous ice clouds with phase values from +1 to +4 . The frontal band to the north contains values from +1 to +3 , while a value of +4 shows up in small areas in the rain bands around tropical cyclone Sinlaku. A significant amount of unknown phase (0) is found to the east of Sinlaku and south of the frontal band. These unknown-phase clouds are low in altitude (high $T_{\mathrm{C}}$ ), are most likely broken given the low values of ECF retrieved, and most closely resemble shallow trade cumulus: marine boundary layer clouds of this type most often populate the unknown-phase category. Liquid clouds with values of -1 and -2 show up north of Sinlaku and the frontal band. A cloud-phase value of -2 is associated with higher values of ECF, and shows that a stronger spectral signature is obtained from more homogeneous and optically thicker clouds (e.g., Nasiri and Kahn, 2008; Kahn et al., 2011).

Figure 5 shows global patterns of cloud thermodynamic phase for 2007. Ice cloud frequencies approach or exceed 80-90\% over the Maritime Continent and adjacent regions, the ITCZ, central Africa, and the tropical portions of South America. These climatological patterns are most similar to those previously obtained from HIRS (Wylie et al., 2005; Stubenrauch et al., 2006), AIRS (Stubenrauch et al., 2010), and other passive sounders (Liou, 1986), with higher magnitudes compared to CALIOP (Hu et al., 2009), MODIS (Yang et al., 2007; Meyer et al., 2007), and ISCCP (Rossow and Schiffer, 1999). These differences in frequency are mostly explained by the data-filtering approach (colder than $-40{ }^{\circ} \mathrm{C}$ in Sassen et al., 2008), the pixel size (larger pixels are more likely to contain an ice signature), and instrument or algorithm sensitivities (e.g., Ackerman et al., 2008).

Despite the hemispheric differences in ice and liquid cloud frequencies, the overall cloud frequency (sum of liquid, ice, and unknown) is very similar between the two oceanic storm tracks (Fig. 5). These values are much larger than the ECF values shown in Fig. 2 because the phase algorithm only tests for the presence of cloud within the AIRS FOV rather than its fractional area or opacity. As expected, there is a high frequency $(50-60 \%)$ of liquid clouds in the subtropical stratocumulus regimes near the continents. However, in comparison to ISCCP, MODIS, and other data sets, the magnitudes of liquid frequency are lower and, correspondingly, the magnitudes of unknown frequency are higher. This is not surprising given that the phase retrieval depends only on an infrared spectral signature. Future algorithm improvements may reduce the fraction of unknown cloud categorization.

Stratocumulus clouds cover approximately $20 \%$ of Earth's surface, but coverage can be as high as $25-40 \%$ over midlatitude oceans (Wood, 2012). AIRS' limitations in lowcloud categorization are very similar to those from HIRS (e.g., Wylie et al., 2005). Approximately $60 \%$ of all liquid clouds are identified by AIRS as unknown when compared to CALIOP cloud phase (Jin, 2012; Jin and Nasiri, 2013). Visual inspection shows this value is higher for trade cumulus and lower for stratocumulus. In general, the AIRS phase product is very conservative in detecting liquid clouds; rarely is an ice cloud (according to CALIOP) identified as liquid by AIRS (Jin, 2012). The AIRS IR phase tests are much more sensitive to ice compared to liquid, partly because of the thermal surface contrast for high cold clouds (e.g., Kahn et al., 2011). A high frequency (50-70\%) of liquid water clouds is 

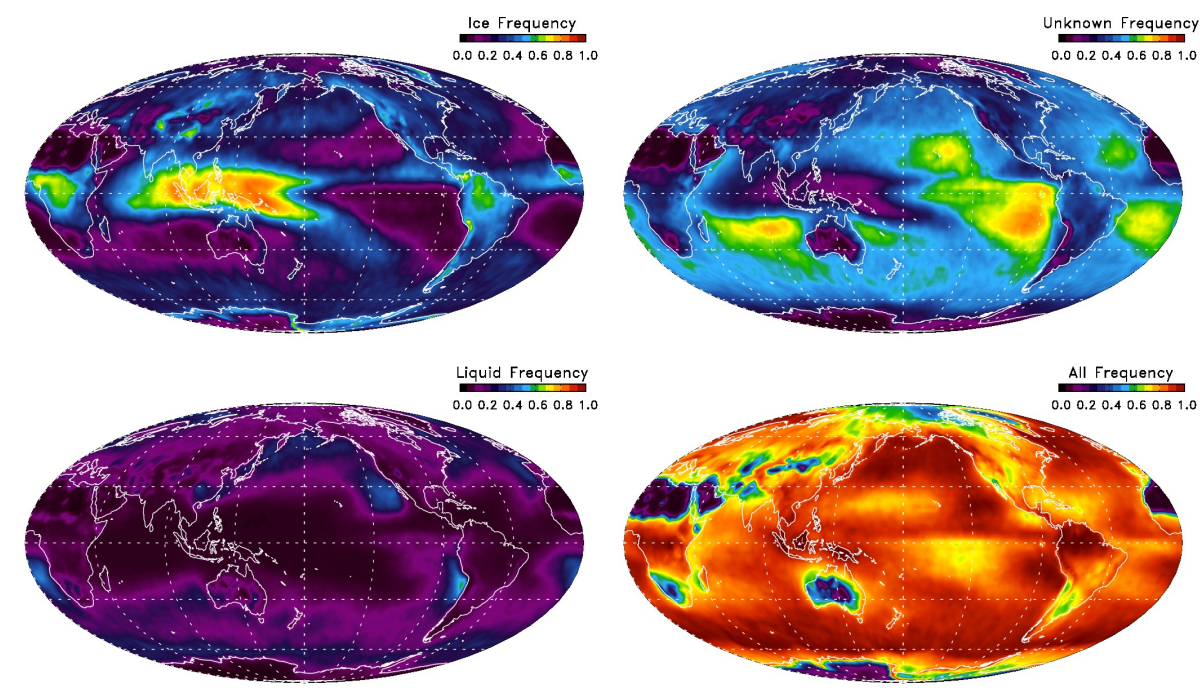

Fig. 5. Cloud thermodynamic phase for ice (upper left), liquid (lower left), unknown phase (upper right), and the sum of the three phases (lower right) for 2007. The relative global frequencies of occurrence (\% of total AIRS FOVs) are $26.5 \%$ for ice, $16.2 \%$ for liquid, and $34.2 \%$ for unknown.

observed in the austral summertime between $50^{\circ} \mathrm{S}$ and the Antarctic coast (Wood, 2012). These high frequencies are also consistent with supercooled liquid cloud frequency observed by the Lidar In-space Technology Experiment (LITE; Hogan et al., 2004) and CALIOP (Hu et al., 2010; Choi et al., 2010). Similar patterns around Antarctica are also observed in other austral summertime months and years, and liquid water frequencies are drastically reduced during austral winter (not shown).

The spatial distributions of the frequency of passed liquid and ice tests are shown in Fig. 6. Values of -2 (both liquid cloud tests passed) show up most frequently along the Antarctic coast, within the confines of the coastal subtropical stratocumulus regimes, and in a small portion of southeast Asia (e.g., Wood, 2012). Values of -1 (one liquid cloud test passed) are more prominent in the subtropics between the two storm tracks, and also westward of the coastal subtropical stratocumulus regimes. A weaker spectral signature implies a lower likelihood that both liquid tests pass, and values of -1 correspond closely to the presence of broken liquid clouds. Positive values indicate passed ice cloud tests. Values of +1 are most prominent over land areas and the tropical Pacific and Indian oceans. Values of +2 are found in similar regions with some additional emphasis on the midlatitude storm tracks. Values of +3 are found in a more confined area of the tropics and smaller areas of the midlatitudes. Values of +4 are the least common and show up within deep convection in the tropical western Pacific, tropical South America, and central Africa, with negligible frequencies elsewhere.

\subsection{Ice cloud property retrievals}

The new ice cloud property retrievals $\tau, D_{\mathrm{e}}$, and $T_{\mathrm{C}, \mathrm{ICE}}$ are shown in Fig. 1. The $T_{\mathrm{C}, \mathrm{ICE}}$ and upper-layer $T_{\mathrm{C}}$ correspond well with each other, although warmer values are observed in places where the AIRS retrieval obtains two layers. This suggests that ice cloud retrievals may be improved in the future by including an additional layer(s). The optically thickest cirrus is located near the center of Sinlaku and in the core of the frontal band. The $D_{\mathrm{e}}$ pattern is more variable (implying higher noise) than $\tau$ and $T_{\mathrm{C}, \mathrm{ICE}}$ and a higher frequency of data dropouts exists because of the more stringent QC compared to $\tau$ and $T_{\mathrm{C} \text {,ICE. However, many distinct granule-scale }}$ patterns emerge. An abundance of cirrus to the south of Sinlaku is observed to have much lower $\tau$ compared to the ice clouds surrounding the eye.

\subsubsection{Ice cloud property retrievals}

The three primary ice cloud products are retrieved simultaneously and are found in the AIRS L2 support product files: $\tau$ (ice_cld_opt_dpth), $D_{\mathrm{e}}$ (ice_cld_eff_diam), and $T_{\mathrm{C}, \mathrm{ICE}}\left(i c e \_c l d t e m p \_e f f\right) . T_{\mathrm{C}, \mathrm{ICE}}$ is considered a less crucial parameter than $\tau$ and $D_{\mathrm{e}}$ since it is already retrieved as a part of the AIRS L2 standard product suite, but much improved $\chi^{2}$ fits and more frequent convergence were obtained when retrieving $T_{\mathrm{C}, \mathrm{ICE}}$ as a third parameter. The first two parameters $\left(\tau\right.$ and $\left.D_{\mathrm{e}}\right)$ are retrieved in log space to prevent negative values. The three parameters are simultaneously retrieved on individual AIRS FOVs that contain ice (anywhere from +1 to +4 tests passed) using an optimal estimation retrieval as a post-processor after the AIRS standard L2 retrieval is completed. The optimal estimation algorithm is derived from 


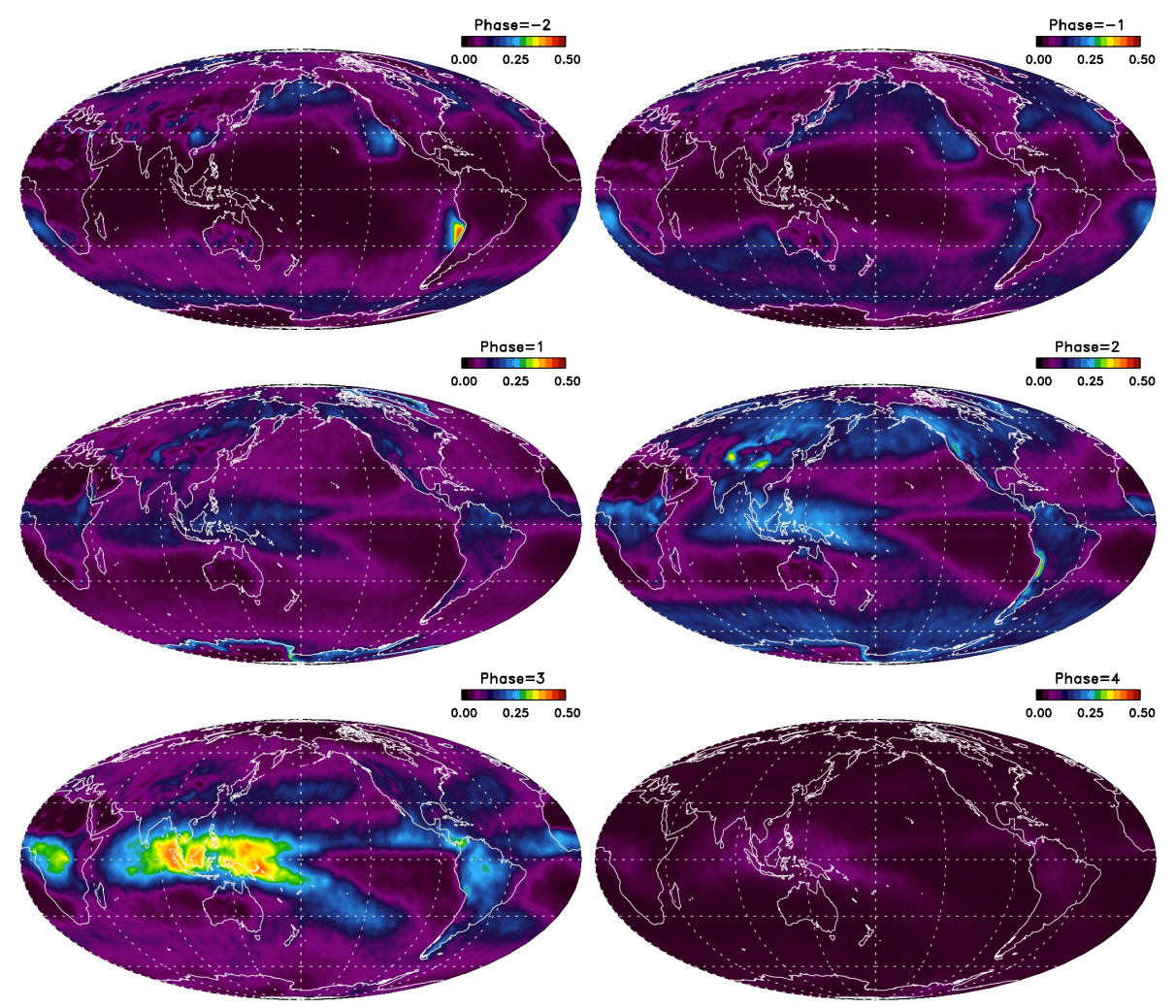

Fig. 6. The various phase tests for liquid (upper row) and ice (middle and lower rows) phases for 2007. In the case of liquid, -2 indicates that the two liquid-phase tests were passed, and -1 indicates only one of the two tests passed. In the case of ice phase, maps are shown for the number of ice-phase tests that passed (1-4). The relative frequencies of occurrence ( $\%$ of total AIRS FOVs) for tests $-2,-1,1,2,3$, and 4 are $7.9 \%, 8.3 \%, 6.7 \%, 10.7 \%, 8.2 \%$, and $0.8 \%$, respectively. Please refer to Sect. 3.1 for an explanation of each phase test.

the Tropospheric Emission Spectrometer (TES) retrieval, described in Bowman et al. (2006). The algorithm minimizes the cost function

$C=\|\boldsymbol{y}-\boldsymbol{F}(\boldsymbol{x}, \boldsymbol{b})\|_{\mathbf{S}_{\varepsilon}^{-1}}^{2}+\left\|\boldsymbol{x}-\boldsymbol{x}_{\mathrm{a}}\right\|_{\mathbf{S}_{\mathrm{a}}^{-1}}^{2}$,

where $\boldsymbol{y}$ is the vector of measured radiances, $\boldsymbol{F}(\boldsymbol{x})$ is the forward-modeled radiance vector, $\boldsymbol{x}$ is the state vector of the parameters retrieved $\left(\tau, D_{\mathrm{e}}\right.$, and $\left.T_{\mathrm{C}, \mathrm{ICE}}\right), \boldsymbol{x}_{\mathrm{a}}$ is the a priori state vector, $\boldsymbol{b}$ is a vector containing fixed atmospheric state variables (temperature profile, water vapor profile, etc.) and observational metadata necessary for calculating the radiances, $\mathbf{S}_{\varepsilon}^{-1}$ is the inverse noise covariance (diagonal for AIRS-footprint retrievals), and $\mathbf{S}_{\mathrm{a}}^{-1}$ is the inverse covariance of the a priori.

For this initial effort, construction of the $\boldsymbol{x}_{\mathrm{a}}$ and $\mathbf{S}_{\mathrm{a}}^{-1}$ matrices is mostly ad hoc. The inputs to our a priori state vector are an assumed $\tau=3.0$ and $D_{\mathrm{e}}=30 \mu \mathrm{m}$, while $T_{\mathrm{C} \text {,ICE }}$ is initially from the AIRS L2 standard product upper-level $T_{\mathrm{C}}$. The fixed first-guess values for $\tau$ and $D_{\mathrm{e}}$ were settled on after investigating more dynamic initial guesses that depended on $T_{\mathrm{C}}$ and other parameters. These other approaches led to poorer spectral radiance fits and reduced occurrences of retrieval convergence.
$\mathbf{S}_{\mathrm{a}}^{-1}$ contains the a priori variances along the diagonal, with zero off-diagonals, and are also assumed to be constants (log_ice_cld_opt_dpth_prior_var $=0.111$, log_ice_cld_eff_diam_prior_var $=0.16$, and ice_cld_ temp_eff_prior_var $=225$ ). These a priori values are consistent with reported histograms of these cloud properties from remote sensing observations. The variances are in practice dependent on many physical variables including cloud and scene type, season, latitude, altitude, and possibly many other factors. Whether independent satellite, in situ, or modelderived data sets are the appropriate proxy for prior first guesses and variances is uncertain and warrants further research. Thus, with this use of assumed constants in the a priori, we caution against quantitatively using the reported error or averaging kernels (described below) until further research is performed.

The solution of the above cost function follows the GaussNewton and Levenberg-Marquardt methods described in Section IV of Bowman et al. (2006). The line-by-line radiative transfer model (LBLRTM) forward model was replaced with the stand-alone AIRS radiative transfer algorithm (SARTA; Strow et al., 2006), and the cloudy sky spectra are calculated from a version of SARTA that is coupled to 
a delta-four-stream (D4S) cloudy radiative transfer program to account for ice cloud scattering (Ou et al., 2013).

Ignoring errors from fixed atmospheric state variables, and assuming that the retrieval is somewhat linear in the neighborhood of the solution (see Sect. 5.4 in Rodgers, 2000), we calculate the solution error covariance as

$\hat{\mathbf{S}}=\left(\mathbf{K}^{T} \mathbf{S}_{\varepsilon}^{-1} \mathbf{K}+\mathbf{S}_{\mathrm{a}}^{-1}\right)^{-1}$

where $\mathbf{K}$ is the Jacobian $(\mathrm{d} \boldsymbol{y} / \mathrm{d} \boldsymbol{x})$, calculated by finite differences. We assume the errors are uncorrelated, and the reported errors are the square roots of the diagonals of $\hat{\mathbf{S}}$. Note that the retrievals for $\tau$ and $D_{\mathrm{e}}$ are performed in natural $\log$ space but are reported in the output files (ice_cld_opt_dpth and ice_cld_eff_diam) in linear space. However, the reported errors ice_cld_opt_dpth_err and ice_cld_eff_diam_err have been left in natural log space; that is,

$i c e \_c l d \_o p t \_d p t h \_e r r=\varepsilon\left(\log _{\mathrm{e}}[\tau]\right)$

and

ice_cld_eff_diam_err $=\varepsilon\left(\log _{\mathrm{e}}\left[D_{\mathrm{e}}\right]\right)$.

The lower (upper) boundaries for the retrieved $\tau$ and $D_{\mathrm{e}}$ can be determined by dividing (multiplying) by the exponential of the reported error fields. For example, the range [lower error, higher error] of the retrieved $\tau$ can be calculated by

$$
\begin{aligned}
& {\left[e^{-i c e \_c l d o p t+d p t h \_e r r} \times i c e \_c l d \_o p t \_d p t h,\right.} \\
& \left.e^{i c e \_c l d \_o p t d p t h \_r r} \times i c e \_c l d \_o p t \_d p t h\right],
\end{aligned}
$$

and the same approach is used for $D_{\mathrm{e}}$. The reported error for $T_{\mathrm{C}, \mathrm{ICE}}$ (ice_cld_temp_eff_err) is in linear space. Again, for reasons given, we caution against using these errors quantitatively. Further discussion regarding error characterization is addressed in Sect. 3.2.4.

The averaging kernel matrix, $\mathbf{A}$, is a measure of the sensitivity of the retrieval to a change in the true state:

$\mathbf{A}=\frac{\partial x_{\text {retrieved }}}{\partial x_{\text {true }}}=\left(\mathbf{K}^{T} \mathbf{S}_{\varepsilon}^{-1} \mathbf{K}+\mathbf{S}_{\mathrm{a}}^{-1}\right)^{-1} \mathbf{K}^{T} \mathbf{S}_{\varepsilon}^{-1} \mathbf{K}$.

The reported scalar averaging kernels (AK) ice_cld_opt_dpth_ave_kern, ice_cld_eff_diam_ave_kern, and ice_cld_temp_eff_ave_kern are from the diagonal of $\mathbf{A}$, and independently range from 0.0 to 1.0 . The $\chi^{2}$ fitting parameter is calculated as

$\chi^{2}=\frac{1}{N} \sum_{i=1}^{N}\left(\frac{\boldsymbol{y}_{i}-[\boldsymbol{F}(\boldsymbol{x})]_{i}}{\varepsilon_{i}}\right)^{2}$,

where $\varepsilon_{i}$ is the radiance error in channel $i$ and $N$ is the number of channels.

\subsubsection{QC and channel selection}

The three most important ancillary parameters are the quality control (QC) indicators for $\tau$ (ice_cld_opt_dpth_QC), $D_{\mathrm{e}}$ (ice_cld_eff_diam_QC), and $T_{\mathrm{C}, \mathrm{ICE}}\left(i c e \_c l d \_t e m p \_e f f \_Q C\right.$ ). For ice_cld_opt_dpth_QC and ice_cld_temp_eff_QC, the range is from 0 to 2 , where $0=$ "best", $1=$ "good", and $2=$ "do not use". We strongly discourage the use of scenes with $\mathrm{QC}=2$ unless users carefully validate the retrieval results or consult with members of the AIRS Science Team. For $i c e \_c l d \_e f f d i a m \_Q C$, only values of 1 and 2 are reported. Since $D_{\mathrm{e}}$ is a very challenging parameter to retrieve and interpret, a conservative QC approach was decided to be most appropriate. The $\tau, D_{\mathrm{e}}$, and $T_{\mathrm{C} \text {,ICE }}$ parameters must be used in conjunction with the QC at the FOV scale, since values with $\mathrm{QC}=2$ are also reported in the AIRS L2 support product. These products are also available as gridded level 3 (L3) files with appropriate QC applied.

The QC indicators are derived from the ice_cld_fit_reduced_chisq $\left(\chi^{2}\right)$ between the simulated and observed $T_{\mathrm{b}}$ 's and scalar AKs ice_cld_opt_dpth_ave_kern, ice_cld_eff_diam_ave_kern, and ice_cld_temp_eff_ave_kern that independently range from 0.0 to 1.0 . The QC indicators derived from combinations of $\chi^{2}$ and AKs for the three retrieval parameters are described in Table 2, and additional retrieval parameters are listed in Table 3. All values are reported in the AIRS L2 support product files. These QC indicators are neither absolute nor quantitative, but should be interpreted as an approximate indicator for robust retrieval values that are obtained from good spectral $T_{\mathrm{b}}$ fits between simulations and observations and higher values of information content. As the QC indicators for these fields are not identical, it is possible that one parameter may have $\mathrm{QC}=$ 0 , while the other parameters may have $\mathrm{QC}=1$ or 2 . The percentage occurrence of each QC value for each retrieval parameter during 2007, where $27.0 \%$ of all AIRS FOVs are identified as containing ice, is shown in Table 4.

An illustrative retrieval for a thin cirrus cloud ( $\tau=0.46$, $D_{\mathrm{e}}=41 \mu \mathrm{m}$, and $T_{\mathrm{C}, \mathrm{ICE}}=213 \mathrm{~K}$ ) located at $15.6^{\circ} \mathrm{N}$ and $132.6^{\circ} \mathrm{E}$ is shown in Fig. 7. There are 59 AIRS channels in the $8-15 \mu \mathrm{m}$ window region that are used for the retrieval (see Appendix C), and are different from those used in Kahn et al. (2008b). The channels were not optimized for maximizing the information content of the retrieved cloud parameters nor were the IR spectra compressed to reduce noise (Huang and Antonelli, 2001; Antonelli et al., 2004) or to increase computational efficiency of the radiative transfer (Liu et al., 2005). Strong water vapor absorption lines were avoided, and channels with relatively low values of NEdT were retained. A smaller set of channels was tried and resulted in a reduced frequency of retrieval convergence. Likewise, for a larger set of channels, the computational expense increased beyond acceptable values. The sensitivity to adjustments in $\tau, D_{\mathrm{e}}$, and $T_{\mathrm{C} \text {,ICE }}$ is also shown in Fig. 7 , and as previous investigations have revealed, the greatest effect on the $T_{\mathrm{b}}$ spectrum is due 
Table 2. Listed is the quality control (QC) determination for the three ice cloud retrieval parameters. The scalar averaging kernels (AK) are for each parameter and the value of $\chi^{2}$ is the measure of fit between the observed and simulated radiances. The QC indicators are neither absolute nor quantitative. The variables ice_cld_fit_reduced_chisq $\left(\chi^{2}\right)$, ice_cld_opt_dpth_ave_kern (AK for $\left.\tau\right)$, ice_cld_eff_diam_ave_kern (AK for $D_{\mathrm{e}}$ ), and ice_cld_temp_eff_ave_kern (AK for $T_{\mathrm{C}, \mathrm{ICE}}$ ) are reported in the AIRS L2 support product files.

\begin{tabular}{llll}
\hline & $\begin{array}{l}\text { Best } \\
(\mathrm{QC}=0)\end{array}$ & $\begin{array}{l}\text { Good } \\
(\mathrm{QC}=1)\end{array}$ & $\begin{array}{l}\text { Do Not Use } \\
(\mathrm{QC}=2)\end{array}$ \\
\hline $\begin{array}{l}\text { Ice Cloud Optical } \\
\text { Thickness }(\tau)\end{array}$ & $\begin{array}{l}\text { Both } \mathrm{AK}>0.8 \\
\text { and } \chi^{2}<10.0\end{array}$ & $\begin{array}{l}\text { Either } \mathrm{AK}>0.8 \\
\text { or } \chi^{2}<10.0\end{array}$ & $\begin{array}{l}\text { Both } \mathrm{AK}<0.8 \\
\text { and } \chi^{2}>10.0\end{array}$ \\
\hline $\begin{array}{l}\text { Ice Cloud Effective } \\
\text { Diameter }\left(D_{\mathrm{e}}\right)\end{array}$ & & $\begin{array}{l}\text { Both } \mathrm{AK}>0.8 \\
\text { and } \chi^{2}<10.0\end{array}$ & $\begin{array}{l}\text { Either } \mathrm{AK}>0.8 \\
\text { or } \chi^{2}<10.0\end{array}$ \\
\hline $\begin{array}{l}\text { Ice Cloud Top } \\
\text { Temperature }\left(T_{\mathrm{C}, \mathrm{ICE}}\right)\end{array}$ & $\begin{array}{l}\text { Both } \mathrm{AK}>0.8 \\
\text { and } \chi^{2}<10.0\end{array}$ & $\begin{array}{l}\text { Either } \mathrm{AK}>0.8 \\
\text { or } \chi^{2}<10.0\end{array}$ & $\begin{array}{l}\text { Both } \mathrm{AK}<0.8 \\
\text { and } \chi^{2}>10.0\end{array}$ \\
\hline
\end{tabular}

to changes in $\tau$. For a fixed value of $\tau$, the $T_{\mathrm{C}, \mathrm{ICE}}$ is not very sensitive to height changes, but the highest sensitivity is seen in the $\mathrm{CO}_{2}$-slicing channels. With $\tau$ and $T_{\mathrm{C}, \text { ICE }}$ fixed, $D_{\mathrm{e}}$ shows the least sensitivity of the three parameters. The wellknown sensitivity in slope across the atmospheric windows is best observed in this example when comparing $D_{\mathrm{e}}=20 \mu \mathrm{m}$ with the other values of $D_{\mathrm{e}}$. This subtle sensitivity shows the challenge of retrieving $D_{\mathrm{e}}$, especially for clouds with low (or high) values of $\tau$. This demonstrates that a robust retrieval methodology like that presented in Bowman et al. (2006) is preferable to an ad hoc look-up table approach (Kahn et al., 2008b).

Some evidence of the ice_cld_opt_dpth_first_guess remains in the results to follow, although only a negligible percentage of retrievals stick to a value near the first guess. For the ice_cld_eff_diam_first_guess, there is no evidence that the retrieval sticks to near the first guess value. However, this parameter is sensitive to the width of the finite difference that is fixed at $10 \mu \mathrm{m}$, which is the $D_{\mathrm{e}}$ interval of the single-scattering properties (Baum et al., 2007). When much finer binning is performed in the plotting of $D_{\mathrm{e}}$, for instance at $1 \mu \mathrm{m}$ intervals (not shown), a much higher frequency of occurrence near the $10 \mu \mathrm{m}$ increments is found than in between the increments.

\subsubsection{Global distributions}

The global ice cloud properties for 2007 are shown in Fig. 8 . The $\tau$ distributions in the tropical western Pacific Ocean contain a narrow band of high values compared to ice cloud frequency. The highest values of $\tau$ are associated with the convective band closest to the ITCZ, while this region is surrounded by a wide latitudinal extent of cirrus with lower values of $\tau$. Furthermore, $\tau$ is higher in the winter oceanic storm tracks (Sect. 3.2.6), and is greatly reduced in the Arctic region (Curry and Ebert, 1992) and also over the cold wintertime east Asian and North American continental regions. Very low values of $\tau$ dominate the subtropical subsidence regions.

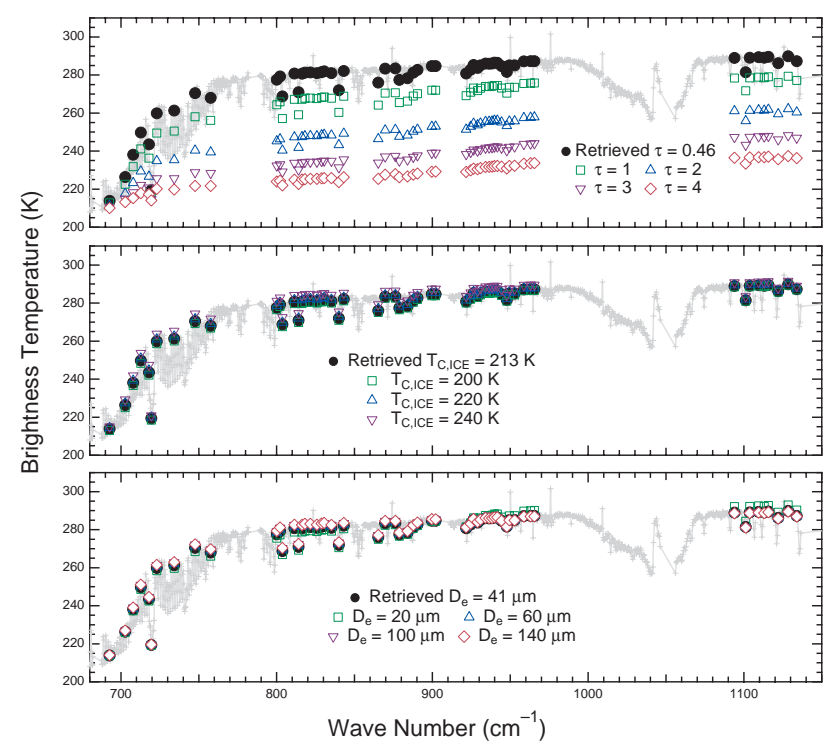

Fig. 7. Shown is an example AIRS spectrum on 6 September 2002 located in granule \#44 (same as Fig. 1). The retrieval is for a relatively thin cirrus cloud and is located at $15.6^{\circ} \mathrm{N}$ and $132.6^{\circ} \mathrm{W}$. The upper panel shows the best fit for $\tau=0.46$, and adjustments to $1.0,2.0,3.0$, and 4.0. The middle panel shows the best fit for $D_{\mathrm{e}}=41 \mu \mathrm{m}$, and adjustments to 20.0, 60.0, 100.0, and $140.0 \mu \mathrm{m}$. The lower panel shows the best fit for $T_{\mathrm{C}, \mathrm{ICE}}=213 \mathrm{~K}$, and adjustments to 200,220 , and $240 \mathrm{~K}$.

The $D_{\mathrm{e}}$ distributions are complex and appear to be nonintuitive. They have a broad minimum in the high latitudes, corresponding closely to $\tau$. $D_{\mathrm{e}}$ also has a minimum over the tropical western and central Pacific Ocean, especially on either side of the ITCZ, where thin cirrus is most common. A small maximum in $D_{\mathrm{e}}$ along the ITCZ is consistent with larger MODIS-derived $r_{\mathrm{e}}$ obtained within deep convective events in the tropics (Yuan and Li, 2010; cf. Fig. 12). Retrievals of $r_{\mathrm{e}}$ from surface-based radar and lidar observations also show somewhat larger values in profiles classified as more convectively active (Protat et al., 2011). These results 
Table 3. Names and descriptions of all ice cloud retrieval parameters found in the AIRS L2 support product files.

\begin{tabular}{|c|c|}
\hline $\begin{array}{l}\text { AIRS L2 support product variable } \\
\text { name }\end{array}$ & Description \\
\hline ice_cld_opt_dpth & $\begin{array}{l}\text { Ice cloud optical thickness }(\tau) \text { in the } \\
\text { retrieval state vector } \boldsymbol{x}\end{array}$ \\
\hline ice_cld_eff_diam & $\begin{array}{l}\text { Ice cloud effective diameter }\left(D_{\mathrm{e}}\right) \text { in the } \\
\text { retrieval state vector } \boldsymbol{x}\end{array}$ \\
\hline ice_cld_temp_eff & $\begin{array}{l}\text { Ice cloud top temperature }\left(T_{\mathrm{C}, \mathrm{ICE}}\right) \text { in the } \\
\text { retrieval state vector } x\end{array}$ \\
\hline$i c e \_c l d \_o p t \_d p t h \_Q C$ & Quality control (QC) flag for $\tau$ (see Table 2) \\
\hline ice_cld_eff_diam_QC & QC flag for $D_{\mathrm{e}}$ (see Table 2 ) \\
\hline ice_cld_temp_eff_QC & QC flag for $T_{\mathrm{C}, \mathrm{ICE}}$ (see Table 2) \\
\hline log_ice_cld_opt_dpth_prior_var & $\begin{array}{l}\text { A priori variance for } \tau \text { from diagonal of } \mathbf{S}_{\mathrm{a}}^{-1} \text {, } \\
\text { fixed to constant value of } 0.111\end{array}$ \\
\hline log_ice_cld_eff_diam_prior_var & $\begin{array}{l}\text { A priori variance for } D_{\mathrm{e}} \text { from diagonal of } \\
\mathbf{S}_{\mathrm{a}}^{-1} \text {, fixed to constant value of } 0.16\end{array}$ \\
\hline ice_cld_temp_eff_prior_var & $\begin{array}{l}\text { A priori variance for } T_{\mathrm{C}, \mathrm{ICE}} \text { from diagonal of } \\
\mathbf{S}_{\mathrm{a}}^{-1} \text {, fixed to constant value of } 225\end{array}$ \\
\hline ice_cld_opt_dpth_ave_kern & $\begin{array}{l}\text { Scalar averaging kernel (AK) for } \tau \text { from } \\
\text { diagonal of } \mathbf{A} \text {, ranges from } 0.0 \text { to } 1.0\end{array}$ \\
\hline ice_cld_eff_diam_ave_kern & $\begin{array}{l}\text { Scalar averaging kernel (AK) for } D_{\mathrm{e}} \text { from } \\
\text { diagonal of } \mathbf{A} \text {, ranges from } 0.0 \text { to } 1.0\end{array}$ \\
\hline ice_cld_temp_eff_ave_kern & $\begin{array}{l}\text { Scalar averaging kernel (AK) for } T_{\mathrm{C}, \mathrm{ICE}} \text { from } \\
\text { diagonal of } \mathbf{A} \text {, ranges from } 0.0 \text { to } 1.0\end{array}$ \\
\hline ice_cld_opt_dpth_first_guess & $\begin{array}{l}\text { First guess of } \tau \text {, fixed to constant value of } 3.0 \text { in the } \\
\text { a priori state vector } x_{\mathrm{a}}\end{array}$ \\
\hline ice_cld_temp_eff_first_guess & $\begin{array}{l}\text { First guess of } T_{\mathrm{C}, \mathrm{ICE}} \text {, varies and is set to the upper- } \\
\text { level AIRS L2 } T_{\mathrm{C}} \text { in the a priori state vector } \boldsymbol{x}_{\mathrm{a}}\end{array}$ \\
\hline ice_cld_eff_diam_first_guess & $\begin{array}{l}\text { First guess of } \tau \text {, fixed to constant value of } 30 \mu \mathrm{m} \text { in } \\
\text { the a priori state vector } x_{\mathrm{a}}\end{array}$ \\
\hline ice_cld_opt_dpth_err & Error estimate for $\tau$ from diagonal of $\hat{\mathbf{S}}$ \\
\hline ice_cld_eff_diam_err & Error estimate for $D_{\mathrm{e}}$ from diagonal of $\hat{\mathbf{S}}$ \\
\hline ice_cld_temp_eff_err & Error estimate for $T_{\mathrm{C}, \mathrm{ICE}}$ from diagonal of $\hat{\mathbf{S}}$ \\
\hline ice_cld_fit_reduced_chisq $\left(\chi^{2}\right)$ & $\begin{array}{l}\text { Chi-squared fit between observed and simulated } \\
\text { AIRS radiances (see Eq. } 4 \text { ) }\end{array}$ \\
\hline
\end{tabular}

Table 4. Percent occurrence of the QC values $(0,1$ or 2$)$ for $\tau, D_{\mathrm{e}}$, and $T_{\mathrm{C}, \text { ICE }}$ for 2007 . These percentages are from the subset of AIRS FOVs that contain ice ( $26.5 \%$ globally during this time period).

\begin{tabular}{lrrr}
\hline & $\begin{array}{r}\text { Best } \\
(\mathrm{QC}=0)\end{array}$ & $\begin{array}{r}\text { Good } \\
(\mathrm{QC}=1)\end{array}$ & $\begin{array}{r}\text { Do Not Use } \\
(\mathrm{QC}=2)\end{array}$ \\
\hline$\tau$ & $64.1 \%$ & $29.0 \%$ & $6.9 \%$ \\
$D_{\mathrm{e}}$ & & $68.1 \%$ & $31.9 \%$ \\
$T_{\mathrm{C}, \mathrm{ICE}}$ & $75.5 \%$ & $20.0 \%$ & $4.5 \%$ \\
\hline
\end{tabular}

appear to contradict retrievals from HIRS (Stubenrauch et al., 2004; cf. Fig. 7). However, the discrepancies with HIRS are probably a result of sampling, binning, and other differences between this study and Stubenrauch et al. (2004). FOVscale comparisons of retrievals between the NOAA HIRS and Aqua AIRS instruments are likely to reveal more meaningful information. Maximum values of $D_{\mathrm{e}}$ are obtained on the subtropical side of the midlatitude jets in both hemispheres over the oceans. There is a decrease in $D_{\text {e }}$ poleward across both storm tracks. There is also some structure in ice cloud frequency and $D_{\mathrm{e}}$ associated with orography in coastal Antarctica, the Andes, and other regions of elevated topography. A much larger data set spanning many years and all 

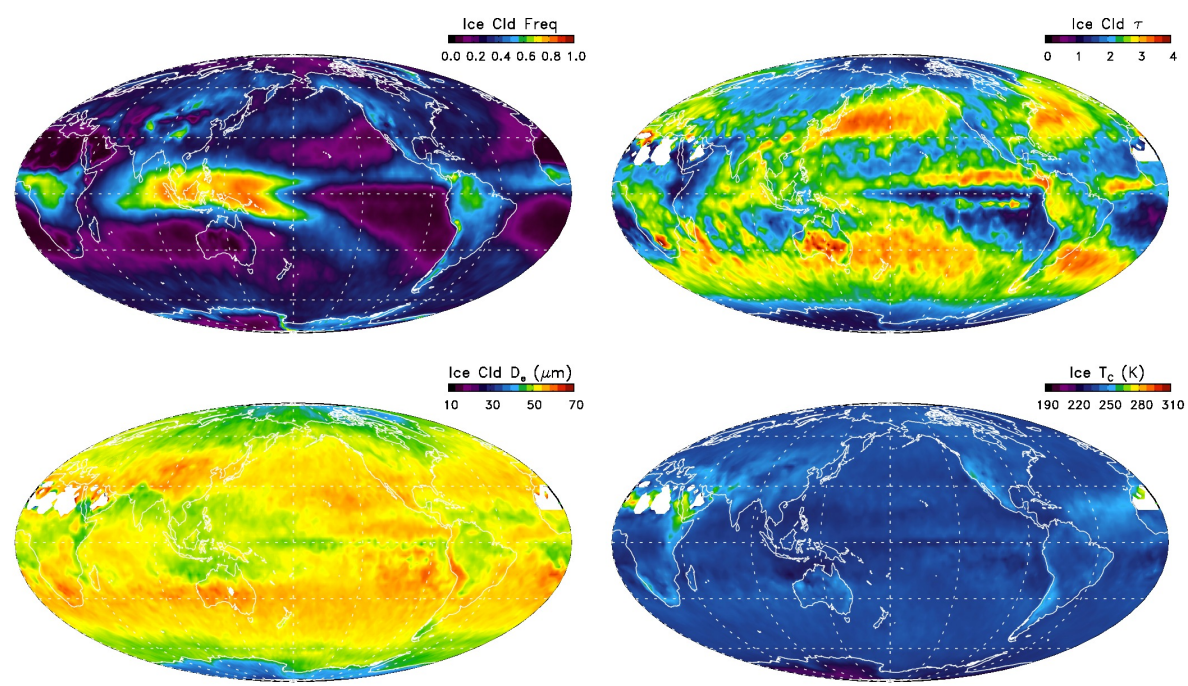

Fig. 8. Ice-phase frequency (upper left, repeat from Fig. 5), $\tau, D_{\mathrm{e}}(\mu \mathrm{m})$, and $T_{\mathrm{C}, \mathrm{ICE}}(\mathrm{K})$ for 2007.
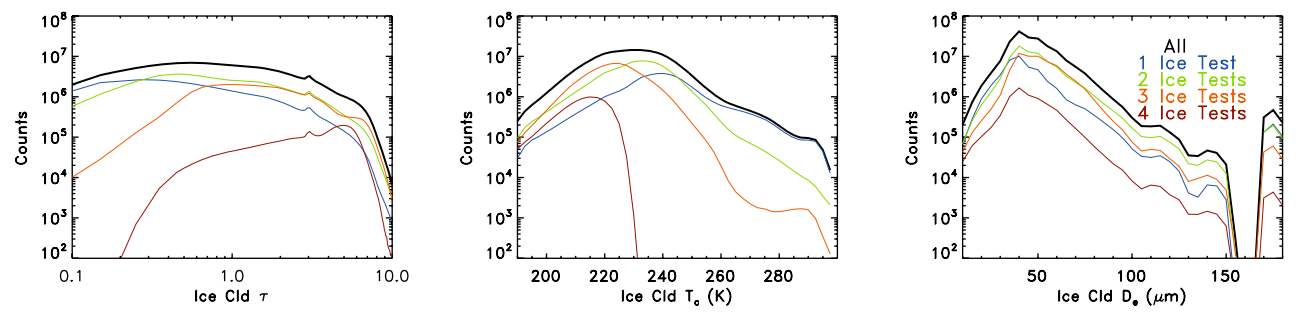

Fig. 9. Histograms of $\tau$ (left), $T_{\mathrm{C}, \mathrm{ICE}}$ (middle), and $D_{\mathrm{e}}$ (right) for 2007. The FOV-scale retrievals that passed 1-4 ice tests are shown separately, as well as histograms for all retrievals (sum of tests 1-4).

seasons is necessary to quantify the behavior of orographic clouds and relate their properties to static stability, vertical velocity, and flow regime (Joos et al., 2010).

The $T_{\mathrm{C}, \text { ICE }}$ pattern is similar to the upper-layer $T_{\mathrm{C}}$ in Fig. 2, but is on average colder. This is expected because $T_{\mathrm{C} \text {,ICE }}$ is a subset of only ice clouds from the ensemble of all cloud types reported in $T_{\mathrm{C}}$.

\subsubsection{Histograms sorted by cloud thermodynamic phase flag}

Histograms of the AIRS ice cloud parameters are shown in Fig. 9. The $\tau$ histogram for all ice tests shows a broad distribution with a peak occurrence near $0.5-0.6$. The a priori value of 3.0 shows up as a small bump. From this, we conclude that the a priori guess for $\tau$ has little impact on the broader retrieval results. For an ice-phase value of +1 , the broad peak in $\tau$ is located closer to $0.2-0.3$, and a reduction in occurrence frequency is seen for $\tau>1.0$. The histogram for +2 has a peak closer to $\tau=0.4-0.5$ and a larger occurrence frequency is observed for $\tau>1.0$ compared to +1 . In the case of +3 , there is a broad peak for $\tau=0.7-1.0$, and a smaller secondary peak for $\tau=6-7$. For +4 , the primary peak is near $\tau=5-6$ and fewer values are observed for $\tau<1.0$. In summary, at higher values of $\tau$, the spectral signature for ice is stronger, and more ice-phase tests are passed. Conversely, more tenuous ice clouds pass fewer tests, and are thus detected less robustly.

A similar pattern is observed for $T_{\mathrm{C}, \mathrm{ICE}}$. The ice clouds are colder on average as more ice tests are passed. There is a small bump in the occurrence frequency around $290 \mathrm{~K}$ for +1 and +3 that suggests biases from multilayered cloud, compensating errors in the retrievals, and/or multiple solutions for very low $\tau$ (e.g., Kahn et al., 2008b). The warm values of $T_{\mathrm{C} \text {,ICE }}$ are most prevalent in the subtropics (Fig. 8). For ice tests +1 to +3 , the peak is near $230 \mathrm{~K}$, with a small peak near $215 \mathrm{~K}$ for +1 . An additional subtle change in slope around $195 \mathrm{~K}$ for +1 and +2 indicates a signature of high altitude and optically thin cirrus near the tropical tropopause layer (TTL). However, these cases do not dominate the overall occurrence frequency. Given the inherent limitations in retrieving thin cirrus from thermal contrast observations, the single layer assumption, and uncertainties in the a priori atmospheric state (e.g., Posselt et al., 2008), the AIRS retrieval is severely underestimating the occurrence of very thin TTL cirrus (Kahn et al., 2008b). CALIOP is better designed for 

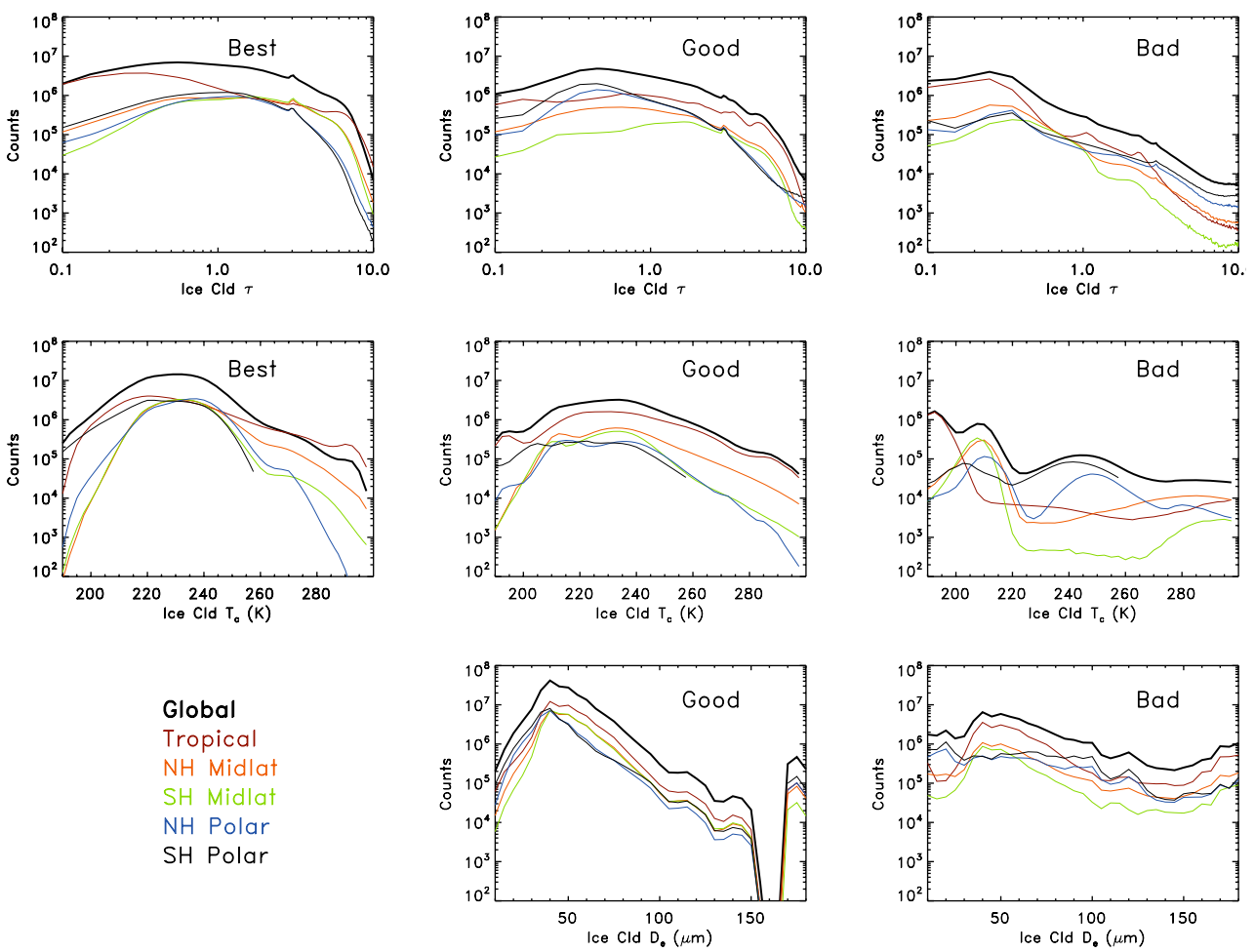

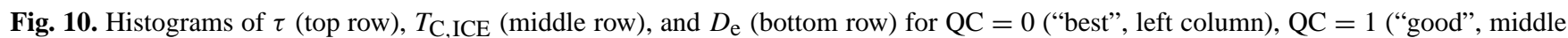
column) and $\mathrm{QC}=2$ ("do not use", right column) retrievals for 2007 . The histograms are organized by latitude band: tropics $\left(30^{\circ} \mathrm{S}-30^{\circ} \mathrm{N}\right)$, $\mathrm{SH}\left(60-30^{\circ} \mathrm{S}\right)$ and $\mathrm{NH}\left(30-60^{\circ} \mathrm{N}\right)$ midlatitudes, and $\mathrm{SH}\left(90-60^{\circ} \mathrm{S}\right)$ and $\mathrm{NH}\left(60-90^{\circ} \mathrm{N}\right)$ polar regions.

investigations involving TTL ice clouds (e.g., Sassen et al., 2008, 2009).

The histograms in Fig. 9 behave differently for $D_{\mathrm{e}}$ compared to $\tau$ and $T_{\mathrm{C}, \mathrm{ICE}}$ in that their shapes are very similar among all ice test combinations. The peak frequency of $D_{\mathrm{e}}$ occurrence varies from 40 to $50 \mu \mathrm{m}$ and drops off substantially at smaller and larger diameters, and a gap in the retrievals around $160 \mu \mathrm{m}$ is apparent. Values in this size range are retrieved but are flagged as bad QC (see Fig. 10). The cause of this is uncertain and warrants further investigation.

\subsubsection{Histograms sorted by QC, latitude band, and error estimates}

The histograms of $\tau, D_{\mathrm{e}}$, and $T_{\mathrm{C}, \mathrm{ICE}}$ are sorted by QC and latitude band in Fig. 10. For QC $=0$, the tropics are dominated by thin cirrus with a peak occurrence frequency of $\tau=0.2$ 0.3 , and a much smaller but notable peak near $\tau=6.0$, consistent with large particles lifted by convection. The polar areas lack high values of $\tau$ as predicted by Curry and Ebert (1992). The midlatitudes are similar to the polar areas for QC $=0$ but with slightly higher occurrences of larger $\tau$. For QC $=1$, there is a shift in the maximum occurrence frequency to lower values of $\tau$. However, the relative ordering of different latitude bands are similar for $\mathrm{QC}=0$ and $\mathrm{QC}=1$. The signature of the a priori $(\tau=3.0)$ is much more variable for $\mathrm{QC}$
$=1$ (maximum in Antarctica, absent in tropics; we speculate this difference may be related to reduced information content in scenes with weaker thermal contrast), while the peak is small but consistent across all latitude bands for $\mathrm{QC}=0$. For $\mathrm{QC}=2$, the peak occurrence frequencies are at low values of $\tau$, which is sensible because these values are more susceptible to bad fits in scenes with multilayered clouds and low information content. For $\mathrm{QC}=0$ values of $T_{\mathrm{C} \text {,ICE }}$, the coldest clouds are found in the tropics, and very warm clouds are found along the fringes of the tropics (see Fig. 6). The extratropics have a more confined $T_{\mathrm{C} \text {,ICE }}$ distribution, consistent with a warmer tropopause and colder surface than the tropics. For $\mathrm{QC}=1$ and $\mathrm{QC}=2$ retrievals of $T_{\mathrm{C}, \mathrm{ICE}}$, the peak occurrence frequency is located at somewhat colder values in the extratropics, but is flatter and warmer in the tropics. The $\mathrm{QC}=2$ retrievals of $T_{\mathrm{C}, \mathrm{ICE}}$ show several peaks and high counts of warm $T_{\mathrm{C}, \mathrm{ICE}}$, indicative of poor fitting and low information content. $\mathrm{QC}=1$ and $\mathrm{QC}=2$ retrievals of $D_{\mathrm{e}}$ peak between 40 and $50 \mu \mathrm{m}$ for all regions.

The fixed values for initial guesses, prior constraints and variances, and the absence of off-diagonal terms may adversely impact the magnitudes and dynamic ranges of the error estimates calculated by Eq. (2). Despite these shortcomings in the $\mathrm{v} 6$ cloud retrieval algorithm, a qualitatively reasonable set of error estimates is obtained. These are presented 

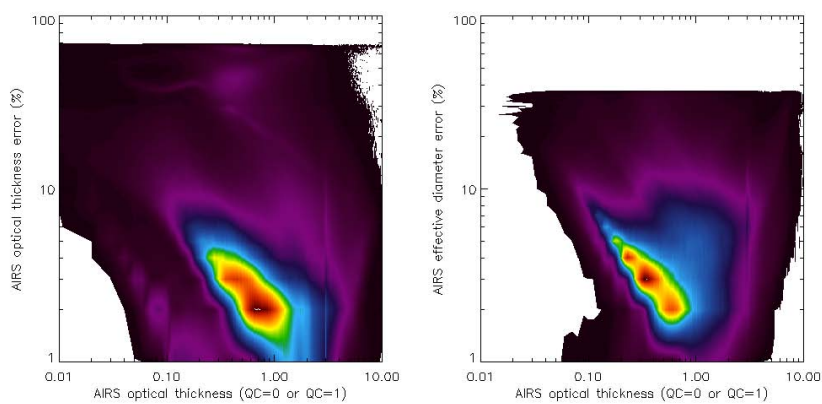

Fig. 11. Shown is the relative error (\%) of $\tau$ (left) and $D_{\mathrm{e}}$ (right) as a function of $\tau$. Only retrievals with $\mathrm{QC}=0(\tau)$ and $\mathrm{QC}=1(\tau$ and $\left.D_{\mathrm{e}}\right)$ are included. The color scale indicates the relative density of occurrences.

as relative errors for $\tau$ and $D_{\mathrm{e}}$ and are shown in Fig. 11. The relative error for $\tau$ decreases from $10 \%$ to $2 \%$ as the magnitude of $\tau$ increases from 0.1 to 1.0 and is somewhat constant for values of $\tau \geq 1.0$. This is consistent with the TES optical depth error estimates in Eldering et al. (2008). There are small populations of retrievals with relative errors between 20 and $50 \%$ near $\tau=1.0$, and errors between 1 and $5 \%$ for very thin cirrus with $\tau \leq 0.1$. With regard to $D_{\mathrm{e}}$, most cloud retrievals have relative errors of approximately $10 \%$ for $\tau=0.1$, reaching a minimum of $1-3 \%$ near $\tau=1.0$. As $\tau$ increases further, the relative error increases to $5-10 \%$ for most values. Throughout the range of $\tau$, a small number of $D_{\mathrm{e}}$ retrievals have relative errors greater than $10 \%$. Previous sensitivity studies (e.g., Cooper et al., 2007; Kahn et al., 2008b; Posselt et al., 2008) suggest much larger uncertainties on the order of 30-50\% are expected for ice cloud $D_{\mathrm{e}}$. These previous studies included the impacts of uncertainties in atmospheric and surface state, ice crystal size and habit distribution, and the vertical geometry of clouds, among others, in retrieval uncertainty estimates of $D_{\mathrm{e}}$. None of these aforementioned factors are included in the present error estimates. Therefore, the fact that the estimates presented in Fig. 11 are low is no surprise.

\subsubsection{Zonal averages}

Zonally averaged histograms of $\tau, D_{\mathrm{e}}$, and $T_{\mathrm{C} \text {,ICE }}$ during 2007 are shown in Fig. 12 and the seasonal variations are detailed in Fig. 13. All retrievals are sorted by land, ocean, day, and night. The oceanic $\tau$ is highest in boreal winter near $40^{\circ} \mathrm{N}$ and is greatly reduced at poleward latitudes. Another broad peak of $\tau$ is found in the austral summer with a reduction near Antarctica. However, the latitudinal $\tau$ gradient is smaller in the summer $\mathrm{SH}$; this pattern is also observed in other years (not shown). In the boreal wintertime midlatitudes, $\tau$ is slightly higher during day over ocean compared to land. The reverse is true in the austral summertime subtropics. There is a minimum of $\tau$ near $10^{\circ} \mathrm{N}$ that is also observed in the MODIS Collection 5 (C5) December-January-
February (DJF) time frame over both land and ocean (Hong et al., 2007). For AIRS, $\tau$ over land is higher in the austral summer and may indicate an increased rate and/or vigor of convection, also in agreement with Hong et al. (2007). In Fig. 12, there is a pronounced minimum of $\tau$ near $10-20^{\circ} \mathrm{N}$ over land. Day and night $\tau$ values differ by as much as a factor of 1.5 , but the diurnal signal is smaller over ocean than over land. In the next section, we will show that the diurnal cycle needs additional regional context to fully describe the complexity and amplitude within the variety of cloud parameters. At smaller scales in the presence of complex topography, the diurnal variations are much larger in magnitude than found in the zonal means.

$T_{\mathrm{C}, \mathrm{ICE}}$ has a very strong diurnal signal over land and less so over ocean, and reaches a maximum value in the subtropics. This is also true in other years (not shown), although the magnitude varies from year to year.

$D_{\text {e }}$ has a minimum in the tropics and polar winters, and a smaller minimum in Antarctica during summer. In the MODIS C5 data set, there is a maximum in $r_{\mathrm{e}}$ during DJF over the deep tropical ocean and a weak minimum over land (Hong et al., 2007). In AIRS, there is a pronounced maximum in the midlatitudes near $30-40^{\circ} \mathrm{N} / \mathrm{S}$ on the equatorial side of the jet stream, with a drop-off poleward of these latitudes. These results are most similar to the CAM5 control run in Gettelman et al. (2010), while other CAM5 experiments tend to exaggerate the higher magnitude of $r_{\mathrm{e}}$ in the midlatitudes compared to AIRS. Although Gettelman et al. (2010) report a cloud top value of $r_{\mathrm{e}}$, a more detailed comparison taking into account the weighting functions of AIRS is warranted. The tendency for maxima in the midlatitudes and minima in the tropics and high latitudes are also seen in other climate model experiments. This includes simulations of transparent ice cloud in the 5th generation of the Max Planck Institute for Meteorology atmospheric general circulation model (ECHAM5) (Joos et al., 2010; cf. Fig. 5), and in modified versions of the CAM3 with various ice nucleation physics parameterizations (Wang and Penner, 2010; Liu et al., 2012).

\section{Additional tests}

Following are two process-based "stress tests" that are designed to gain further insight into the initial performance of the AIRS cloud products. The first test quantifies the variations of key cloud parameters at two local times (01:30 and 13:30 LT) over the Maritime Continent, where there is a very pronounced diurnal cycle in convective ice cloud and rainfall (Neale and Slingo, 2003; Nesbitt and Zipser, 2003; Tian et al., 2006; Qian, 2008). The second test composites midlatitude cyclones in the two hemispheres using a previously published methodology by Naud et al. (2006, 2010). Substantial differences in cloud structure are found between the $\mathrm{NH}$ winter and SH summer storm tracks, which are exaggerated 

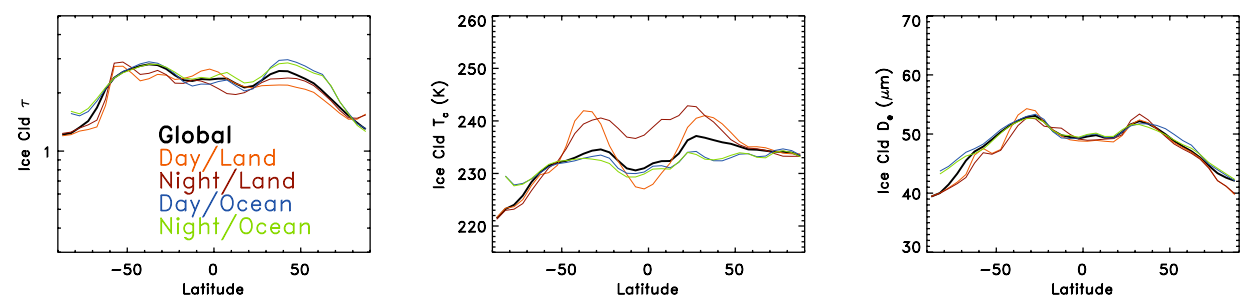

Fig. 12. Zonal averages of $\tau$ (left), $T_{\mathrm{C}, \mathrm{ICE}}$ (center), and $D_{\mathrm{e}}$ (right) for 2007 . Only retrievals for QC $=0$ and 1 are used. Shown are the global results as well as the day vs. night and the land vs. ocean distributions.
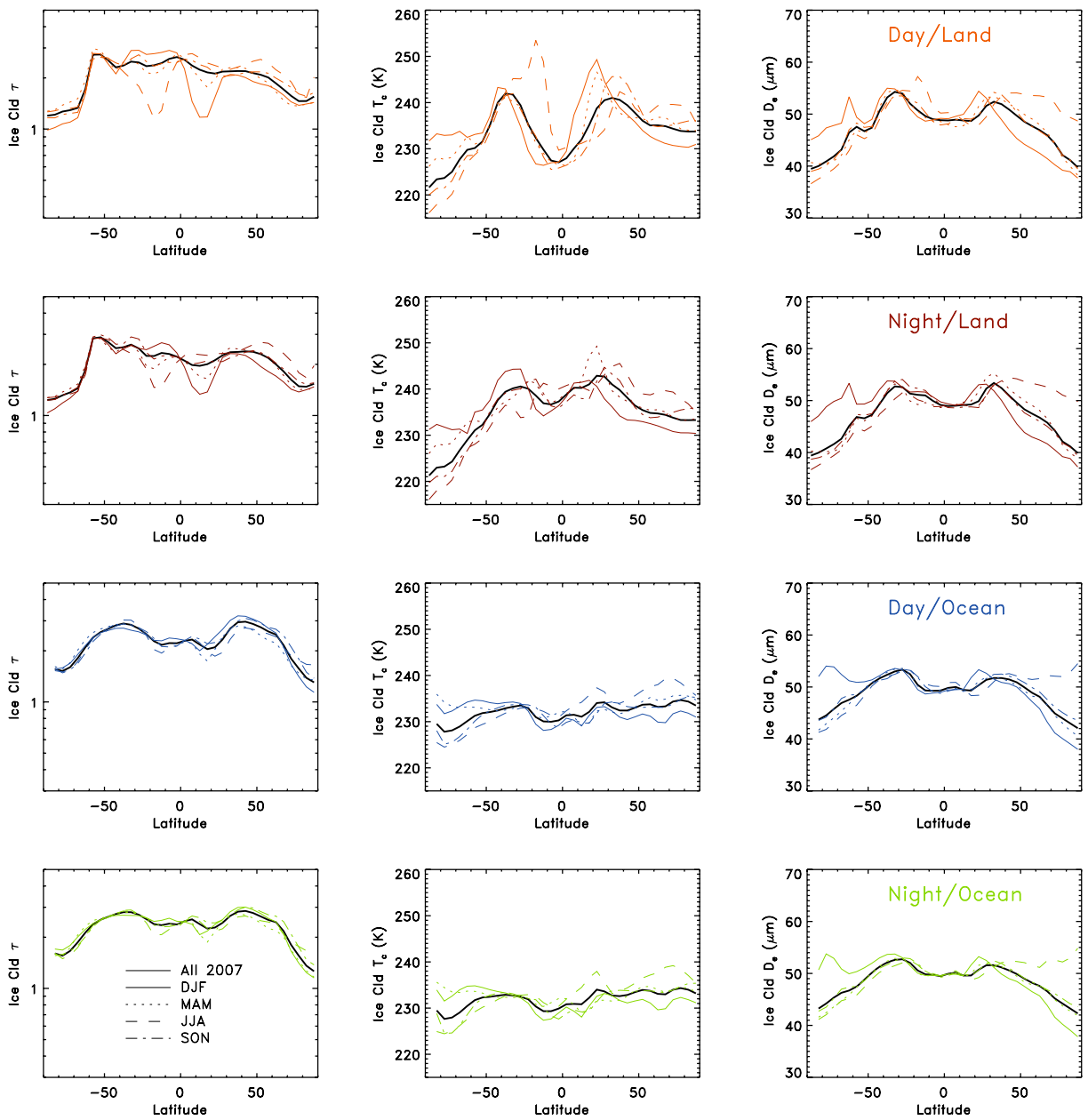

Fig. 13. Zonal averages of $\tau$ (left column), $T_{\mathrm{C}, \mathrm{ICE}}$ (center column), and $D_{\mathrm{e}}$ (right column) for all of 2007, and also for DJF, MAM, JJA, and SON. The global results are in black (repeated from Fig. 12), while the seasonal day vs. night and land vs. ocean distributions are highlighted in color.

further when placed in proximity to midlatitude cyclone centers.

\subsection{Diurnal variations of ice clouds in the Maritime Continent}

The diurnal cycle of clouds, humidity, and precipitation has been quantified in recent years with global satellite data sets (e.g., Chen and Houze, 1997; Rossow and Schiffer, 1999; Yang and Slingo, 2001; Nesbitt and Zipser, 2003; Tian et al., 2004, 2006). Although coarsely gridded traditional general circulation models (GCMs) continue to struggle in capturing the behavior of the diurnal cycle (e.g., Yang and Slingo, 2001; Tian et al., 2004; Dai, 2006), the multiscale modeling framework (MMF or superparameterization) GCMs (e.g., Zhang et al., 2008; Pritchard and Somerville, 2009) or 
global cloud-resolving models (e.g., Sato et al., 2009) have proven to be more representative of its amplitude, phase, and other complexities. The amplitude and phase of the diurnal cycle are strongly dependent on the region (e.g., landsea contrast, topography) and physical parameter of interest, including cloud-related quantities like precipitation, cloud fraction, height, and $\tau$ (Cairns, 1995; Sato et al., 2009). A climate change signal in either the amplitude or phase of the diurnal cycle can have profound impacts on climate trends through the modulation of the daily timing of maximum (or minimum) cloud reflection, and the absorption and re-emission of infrared radiation by high ice clouds (e.g., Cairns, 1995). Convective precipitation (Nesbitt and Zipser, 2003; Dai, 2006), cloud frequency/amount (Chen and Houze, 1997; Rossow and Schiffer, 1999; Tian et al., 2004), and outgoing longwave radiation (e.g., Taylor, 2012) are perhaps the best-observed cloud-related quantities over the diurnal cycle.

It has been well documented that there is a clear landsea contrast for the diurnal cycle of high clouds (cloud tops above $440 \mathrm{hPa}$ ) (e.g., Yang and Slingo, 2001; Tian et al., 2004). High-cloud amount over tropical land is observed to have a distinct minimum during midday, with a maximum in the evening and at night (Cairns, 1995; Rossow and Schiffer, 1999; Tian et al., 2004). In contrast, high-cloud amount over tropical oceans is observed to have a minimum during early morning and a maximum in the afternoon (e.g., Tian et al., 2004). Stubenrauch et al. (2006) shows that a maximum in tropical high-cloud amount is obtained over land during evening and night, while thin cirrus maximizes early in the afternoon, with an overall minimum in high-cloud amount around solar noon. Using CALIOP observations, Sassen et al. (2009) show that diurnal differences in thin versus thick ice cloud frequency strongly depend on the proximity to land and ocean, and can be of opposite sign depending on the range of $\tau$.

Previous studies (e.g., Neale and Slingo, 2003; Tian et al., 2006; Qian, 2008) have shown that the diurnal cycle is very strong in the Maritime Continent, and it may play a fundamental role in the global climate. The AIRS instrument samples two times during the diurnal cycle at 01:30 and 13:30 LT. There are geographical locations and geophysical parameters for which AIRS provides no diurnal variability information because maxima or minima occur in between the AIRS local sampling times. Fortunately, over the Maritime Continent, with its strong diurnal maxima and minima driven by heating differences imposed by land-ocean contrasts, the local crossing time of AIRS lends itself well to sampling important aspects of the convective diurnal cycle. Initial results of the diurnal variability of AIRS ice cloud frequency, $\tau$, and $D_{\mathrm{e}}$ are shown in Fig. 14. The diurnal cycle of ice cloud frequency is not especially large: generally less than $10-20 \%$. In the case of $\tau$, the diurnal differences exceed a factor of 2 and are highest over and adjacent to the islands. The minimum (maximum) at 13:30 LT (01:30 LT) over the islands (adjacent oceans) are consistent with the spatial and temporal
Mean Value
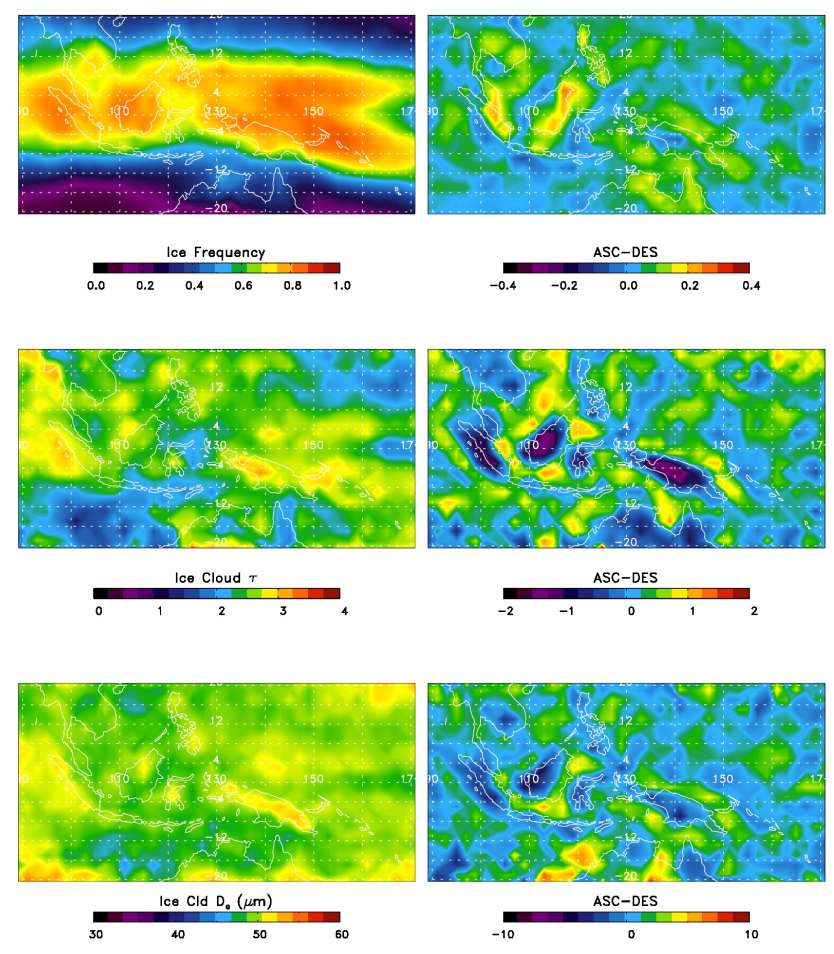

Fig. 14. AIRS diurnal variations of ice cloud properties over the Maritime Continent during 2007 for the mean value (left column) and the ascending-descending differences (13:30-01:30 LT, right column). Shown are ice cloud frequency (top row), $\tau$ (middle row), and $D_{\mathrm{e}}$ (bottom row).

variations of TRMM convective features (Nesbitt and Zipser, 2003). These patterns are also simulated by the $7 \mathrm{~km}$ NICAM (Sato et al., 2009), which shows evidence for a $3 \mathrm{~h}$ lag of the maximum in high-cloud amount behind the maximum in precipitation (e.g., Tian et al., 2004).

The diurnal differences for $D_{\mathrm{e}}$ are less pronounced than for $\tau$, with some suggestion of structure near the individual islands. However, $D_{\mathrm{e}}$ appears to be spatially out of phase with $\tau$ in many locations on a daily basis (not shown). The diurnal variability is also either more or less emphasized on either side of the traverse range of Papua New Guinea depending on the time period investigated (not shown). Protat et al. (2011) show that, using ground-based retrievals at the Darwin Atmospheric Radiation Measurement (ARM) program observing site, the magnitude of $r_{\mathrm{e}}$ is dependent on the large-scale flow regime and the type of ice cloud present (deep convective, anvil cirrus, and thin cirrus).

This initial snapshot of the diurnal cycle in the Maritime Continent confirms that its amplitude is dependent on cloud parameter and geographical location. The day-night differences in AIRS demonstrate skill and are offering new insights on the diurnal variability of ice cloud properties, as well as thermodynamic phase in many other geophysical 
regimes. Furthermore, FOV-scale matches of temperature, water vapor, and cloud properties can now be composited upwards from the FOV scale, preserving rich and detailed spatial and temporal variability.

\subsection{Midlatitude cyclone composites}

While there is ample observational evidence of a climatechange-induced poleward shift in the storm tracks in both hemispheres (Bengtsson et al., 2006; Johanson and Fu, 2009; Bender et al., 2012), change in the frequency and intensity of midlatitude cyclones within each of the storm tracks is much less certain (Schneider et al., 2010). One particularly successful and rigorous approach to evaluate presentday climate model simulations of midlatitude cyclones is to composite their dynamic and thermodynamic features in a common coordinate system relative to the cyclone center (e.g., Lau and Crane, 1995; Naud et al., 2006; Field and Wood, 2007). Field et al. (2008) used a number of CAM3 physics perturbations to test this approach, including a new microphysics scheme, and their simulations were compared to cloud amount, rain rate, and near-surface winds derived from MODIS, AMSR-E, and QuikSCAT, respectively. Field et al. (2008) found that all model perturbations produced too much thick high cloud within cyclones, although important differences were found between the perturbations. The thick high-cloud bias was significantly reduced in the CAM5 (Kay et al., 2012). CAM3 also showed strong relationships of high-cloud fraction with cyclone intensity and column water vapor amount, while satellite observations suggest a strong relationship only between high-cloud fraction and cyclone intensity (Field et al., 2008). Given the availability of temperature and water vapor mixing ratio profiles from AIRS in conjunction with the new cloud parameters reported in this work, this topic warrants continued investigation.

Composites from the UK Met Office atmosphere model with ISCCP cloud type occurrence frequency and their shortwave radiative effects (Bodas-Salcedo et al., 2012) show that the SH surface shortwave bias in CMIP3 described by Trenberth and Fasullo (2010) is due largely to a dearth of low clouds in the cold sector of cyclones. This bias was partly mitigated by improving the representation of clouds in shear-dominated boundary layers. However, Bodas-Salcedo et al. (2012) speculate that large biases may remain in anticyclones that also contain significant low cloudiness. Furthermore, biases remain in the cold air sector from poor simulations of midlevel clouds; in particular the UKMO model places midlevel clouds too close to the cyclone center, and produces too few of them.

The new collection of AIRS cloud products provides additional constraints for model evaluation. Using January 2007 AIRS cloud property retrievals, we construct cyclonecentered composites separately for SH and NH oceanic cyclones using the method of Naud et al. (2012). Despite the sample size limitations, AIRS composites of cloud cover are seen to be consistent with previous studies (e.g., Field and Wood, 2007) and the new products provide additional information on clouds in cyclones. Here we discuss differences and similarities between $\mathrm{NH}$ winter and $\mathrm{SH}$ summer cyclones. For convenience, SH cyclone composites are reversed along the north-south axis, so that the poleward side is at the top of each figure. This allows direct comparison between the two hemispheres.

The total ECF, upper layer $T_{\mathrm{C}}$, and lower layer $T_{\mathrm{C}}$ fields for the $\mathrm{NH}$ and $\mathrm{SH}$ composites are shown in Fig. 15. The highest ECF occurs along the warm front in both hemispheres, while elevated values extend poleward and along the cold front in the SH (Field and Wood, 2007). The upper-level $T_{\mathrm{C}}$ is coldest to the north of the cyclone center in the $\mathrm{NH}$. In the $\mathrm{SH}$, the coldest upper-level $T_{\mathrm{C}}$ is found in the warm front region, and the warmest $T_{\mathrm{C}}$ is equatorward, at the back of the cold front, where open-cell convective tops generally occur at low altitudes. For lower-level $T_{\mathrm{C}}$, a similar pattern to upper-level $T_{\mathrm{C}}$ is seen in the $\mathrm{NH}$ (aside from higher values of $T_{\mathrm{C}}$ ); however, the coldest lower-level $T_{\mathrm{C}}$ is rotated poleward in the $\mathrm{SH}$ compared to the upper-level $T_{\mathrm{C}}$. This suggests fundamental differences in multilayer cloud structure between $\mathrm{SH}$ and $\mathrm{NH}$ cyclones or between summer and winter cyclones. These fundamental differences deserve a thorough study with multiple years of data. Recall that these particular cloud fields include all cloud types and structures. Below, the composites will be sorted by cloud thermodynamic phase.

The cloud occurrence frequency of all cloud types and the three phase categories (ice, liquid, and unknown) are shown in Fig. 16. The cloud frequency (Fig. 16) and ECF (Fig. 15) fields have larger differences poleward of the cyclone center in the $\mathrm{NH}$ compared to the $\mathrm{SH}$. This strongly suggests that clouds in the NH cyclone composites are optically thin poleward of the storm center. Ice clouds are most common poleward and eastward of the cyclone center in the $\mathrm{NH}$ (Field and Wood, 2007), and this pattern is rotated slightly more eastward in the $\mathrm{SH}$, with an extension equatorward into the warm sector not seen in the NH. However, the peak frequency is higher in the $\mathrm{NH}$, as with total cloud frequency. There is a very high occurrence of liquid cloud poleward and west of the cyclone center in the $\mathrm{SH}$, while an opposite pattern appears in the $\mathrm{NH}$ with much less liquid frequency overall. The unknown category is most frequent in the cold sector behind and along the cold front and has a higher magnitude in the $\mathrm{NH}$. This is consistent with the presence of open-cellular cumulus and the difficulty of assigning cloud phase because the cloud tops are frequently located in the mixed-phase temperature range (e.g., Nasiri and Kahn, 2008; Klein et al., 2009).

The ice cloud properties are shown in Fig. 17, with a composite image of ECF restricted to ice clouds. The $\mathrm{SH}$ and $\mathrm{NH}$ patterns and magnitudes of ice cloud ECF are more similar than that for the total ECF shown in Fig. 15. There are some important differences between the $\mathrm{SH}$ and $\mathrm{NH}$ cyclones highlighted by Fig. 17. The warm (cold) front is more prominent in the $\mathrm{NH}(\mathrm{SH})$. In both hemispheres, the highest values of 


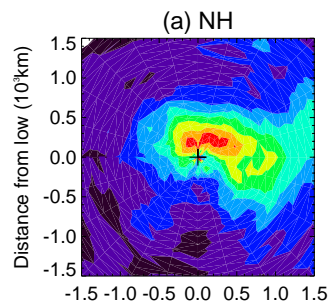

(d) $\mathrm{SH}$

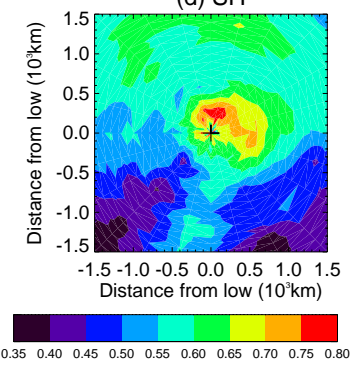

upper+lower layer ECF (b) $\mathrm{NH}$

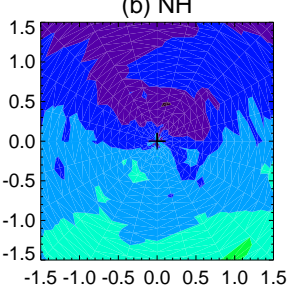

(e) $\mathrm{SH}$

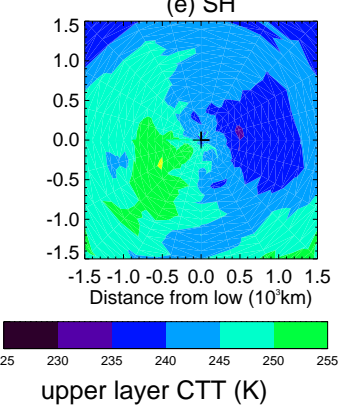

(c) $\mathrm{NH}$

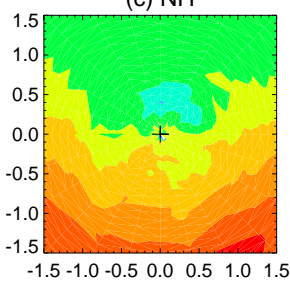

(f) $\mathrm{SH}$

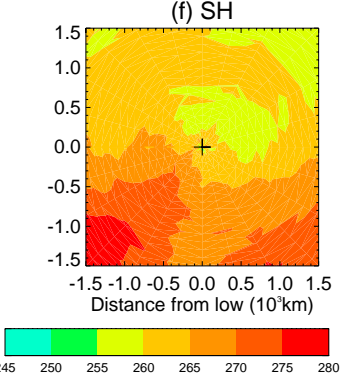

lower layer CTT (K)

Fig. 15. Midlatitude cyclone composites for January 2007 for the total ECF, upper-level $T_{\mathrm{C}}$, and lower-level $T_{\mathrm{C}}$ in the (a)-(c) NH and (d)-(f) SH.

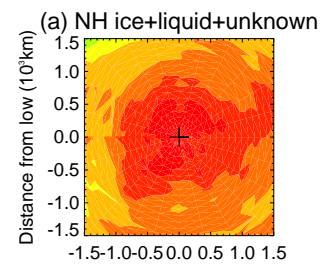

(e) $\mathrm{SH}$

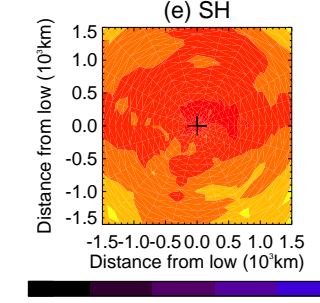

(b) $\mathrm{NH}$ ice

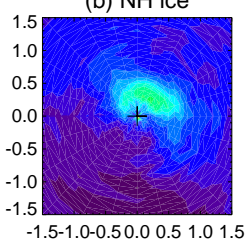

(f) $\mathrm{SH}$

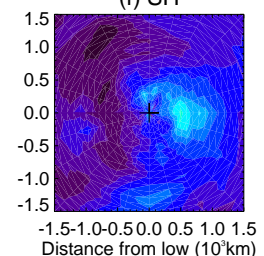

(c) $\mathrm{NH}$ liquid

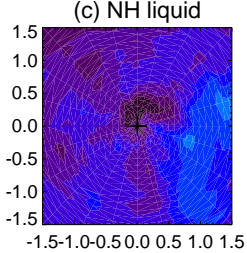

(g) $\mathrm{SH}$

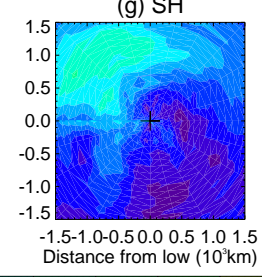

(d) $\mathrm{NH}$ unknown

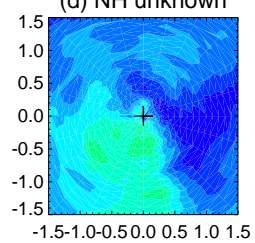

(h) $\mathrm{SH}$

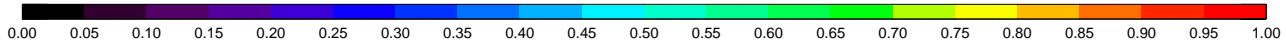

Cloud frequency

Fig. 16. Midlatitude cyclone composites of cloud frequency and ice, liquid, and unknown phase clouds for (a)-(d) the NH and (e)-(h) SH during January 2007.

ice cloud ECF are closer to the cyclone center when compared to the total ECF in Fig. 15. The $\tau$ patterns also track ice cloud ECF patterns. There are higher values of $\tau$ in the $\mathrm{NH}$, and again a greater emphasis on the warm (cold) front in the $\mathrm{NH}(\mathrm{SH})$. In the case of $D_{\mathrm{e}}$, higher values occur equatorward of the cyclone center in both hemispheres. However, higher values are found in the $\mathrm{SH}$, and the hemispheric differences are larger poleward of the cyclone center. $T_{\mathrm{C}, \mathrm{ICE}}$ is much colder than the upper-level $T_{\mathrm{C}}$ shown in Fig. 15 and is consistent with it being an ice cloud subset of all cloud types. Ice clouds are slightly colder in the SH compared to the $\mathrm{NH}$, which is surprising considering that these data are from the austral summer and boreal winter. This may indicate that large-scale cloud ice conditions are always colder in the $\mathrm{SH}$, as found when comparing winter cyclones in both hemispheres in Naud et al. (2012). The coldest $T_{\mathrm{C}, \mathrm{ICE}}$ are found poleward and eastward of the cyclone center and the warmest are found in the cold sector in the $\mathrm{NH}$ (consistent with Fig. 15), although the relative frequency of ice in the cold sector is only between 10 and $30 \%$ (Fig. 16). In the SH, this contrast is slightly rotated so most of the eastern side ice clouds are colder than their western side counterparts. Again, this could be a seasonal feature, which we intend to explore further as a large set of AIRS data becomes available. 

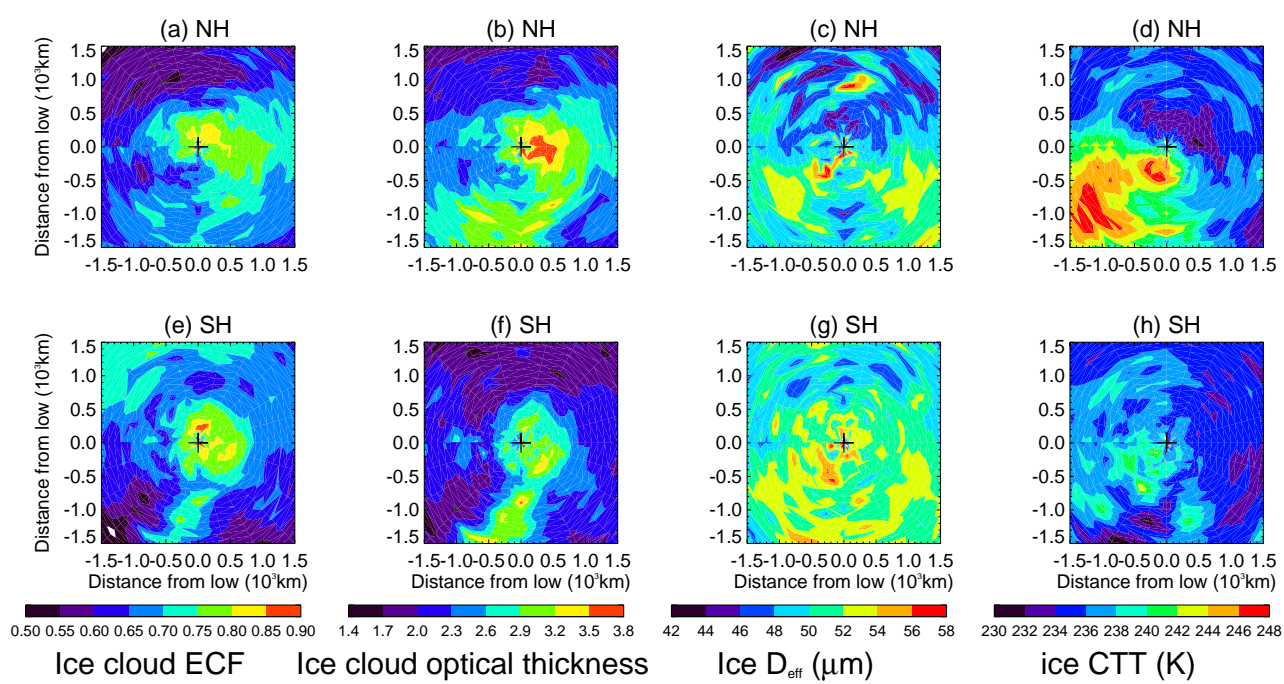

Fig. 17. Same as Fig. 16, except for ice cloud ECF, $\tau, D_{\mathrm{e}}$, and $T_{\mathrm{C}, \mathrm{ICE}}$.

\section{Discussion and summary}

We describe the retrieval methodology and initial results of the Atmospheric Infrared Sounder (AIRS) version 6 (v6) and Advanced Microwave Sounding Unit (AMSU) (Chahine et al., 2006) instrument suite cloud products. The cloud top properties (temperature/pressure/height and effective cloud fraction) are obtained for up to two layers in the AIRS level 2 (L2) standard product, and are now reported at the AIRS field-of-view (FOV) resolution. Significant improvements in cloud height assignment over version 5 (v5) are shown with FOV-scale comparisons to cloud vertical structure observed by the CloudSat $94 \mathrm{GHz}$ radar (Stephens et al., 2008) and the Cloud-Aerosol LIdar with Orthogonal Polarization (CALIOP; Winker et al., 2010). These improvements are obtained for most observing conditions including land, ocean, day, and night. More realistic small-scale cloud structures are now observed, partly due to improvements in boundary layer cloud characterization.

Several new cloud products are now reported in the AIRS L2 support product files. The first is the cloud thermodynamic phase that identifies clouds as "ice" or "liquid", with an additional category "unknown" for confidently detected clouds that do not contain an easily identifiable ice or liquid signature. Jin and Nasiri (2013) showed that AIRS very consistently detects ice, but not liquid, when compared to CALIOP. Ice cloud frequencies in excess of $80-90 \%$ are found over the Maritime Continent, tropical South America and central Africa. Larger amounts of ice are found in the winter storm track compared to the summer storm track. Very high frequencies of liquid cloud occurrence are detected around Antarctica in the austral summer and the patterns and magnitudes are consistent with previous studies (e.g., Hu et al., 2010; Choi et al., 2010; Wood, 2012). Although the stratocumulus regions contain primarily liquid phase, the trade cumulus regions are dominated by unknown phase, and this is consistent with the weak IR radiance cloud-phase signal from these cloud types.

Three other new cloud products include ice cloud effective diameter $\left(D_{\mathrm{e}}\right)$, ice cloud optical thickness $(\tau)$, and ice cloud top temperature $\left(T_{\mathrm{C}, \mathrm{ICE}}\right)$, and are derived using an optimal estimation approach adapted from the Tropospheric Emission Spectrometer (TES; Bowman et al., 2006) cloud retrieval methodology restricted to AIRS FOVs that contain ice clouds. Both $\tau$ and $D_{\mathrm{e}}$ are retrieved simultaneously along with $T_{\mathrm{C} \text {,ICE }}$ to obtain better fits and more frequent retrieval convergence than if $\tau$ and $D_{\mathrm{e}}$ are retrieved alone. Quality control $(\mathrm{QC})$ parameters are described that streamline the use of these ice cloud properties and are based on the quality of radiance fits between simulations and observations and the magnitudes of the averaging kernels. Distributions of $\tau$ and $D_{\text {e }}$ for 2007 show that $\tau$ is highest in the deep tropics and oceanic midlatitude storm tracks, and lowest in the subtropics, the Arctic, and over Antarctica. The region of high $\tau$ in the deep tropics is much more confined in latitude than the high occurrence frequency of ice cloud, which extends to the edge of the subtropics; this pattern captures the narrow region of deep convective clouds and adjacent thin cirrus. The distributions of $D_{\mathrm{e}}$ peak between 30 and $40^{\circ} \mathrm{N} / \mathrm{S}$, with minima in the broad region of the tropics and high latitudes (Curry and Ebert, 1992). A small increase in $D_{\mathrm{e}}$ associated with deep tropical convective events is shown to be consistent with both MODIS (Yuan and Li, 2010) and surface-based radar and lidar retrievals (Protat et al., 2011).

The zonal mean differences of the diurnal variability of ice cloud properties are not as revealing as regional-scale differences. The regional context is important for grasping the rich complexity of the diurnal variability that is actually present in AIRS data. The diurnal variability of $\tau$ in the 
Maritime Continent is shown to be significantly larger than diurnal variability for the total cloud fraction, ice cloud frequency, and $D_{\mathrm{e}}$, and is linked to the spatial pattern of the convective lifecycle that is anchored to the island archipelago morphology. The distributions and magnitudes are in significant agreement with seminal observations made by the Tropical Rainfall Measuring Mission (TRMM; Nesbitt and Zipser, 2003) and the International Satellite Cloud Climatology Project (ISCCP; Rossow et al., 2005) data. The infraredbased retrievals of AIRS are providing unique decadal-scale and global snapshots of clouds within the diurnal and annual cycles at all latitudes.

The interhemispheric differences in the total cloud amount are rather small. However, the cloud-phase frequencies and ice cloud properties show substantially larger differences. To put the problem into an atmospheric process-based framework, we composited cloud properties using the approach of Naud et al. (2006) to quantify structural differences between winter $\mathrm{NH}$ and summer SH midlatitude cyclones. Although only one month (January 2007) is shown, which represents the boreal winter and austral summer, the observed structural differences of cloudiness in proximity to the warm and cold fronts is consistent with previous works. This includes a very high frequency of liquid clouds poleward of summer SH cyclone centers, and a much larger occurrence of unknown clouds in open-cellular convection in the cold sector behind the winter NH cold fronts. The frequency of cirrus is highest along the warm (cold) front in the $\mathrm{NH}(\mathrm{SH})$, consistent with Naud et al. (2012). The new ice cloud property retrievals show elevated $D_{\mathrm{e}}$ along the warm and cold fronts, and much lower values poleward of the cyclone centers in both hemispheres. However, the overall values of the boreal winter $D_{\mathrm{e}}$ are lower than in the austral summer. Further research will quantify the full range of seasonal and interannual variability.

\section{Future work}

Many improvements in the retrieval approach should be investigated further. Multilayered clouds could be added to the scattering calculation. Since AIRS reports two layers in the standard retrieval, including the lower layer in a radiative transfer calculation is a possibility. However, the approach for treating the lower (or additional) layer(s) raises a large set of complications. As phase is only assigned for the top of the upper cloud layer, assigning a phase for a lower layer is ambiguous (and untested), but could be approximated by retrieved values of $T_{\mathrm{C}}$. Additionally, it is not certain whether the lower layer will have a signal that is unambiguous enough to retrieve the optical and microphysical properties, whether it is liquid, ice, or possibly mixed phase. Another approach is to limit the most rigorous retrievals to the CloudSat/CALIPSO track and better constrain the verti- cal structure and phase, but it is unclear how much additional information the active sensors will provide.

The ice cloud property retrieval is a post-processor that runs after the AIRS standard level 2 cloud-clearing algorithm. It is possible to include some (or all) elements of the cloud retrieval at earlier steps in the cloud-clearing process to improve the overall L2 geophysical retrieval results. For instance, a simple estimate of the cloud thermodynamic phase in the iterative cloud-clearing steps may improve the L2 full geophysical state retrieval. The record of collocated matchups of AIRS and MODIS data at the FOV/pixel scale is now over $10 \mathrm{yr}$ long. Advancements in the instrument calibration, ground-truth comparisons through validation, and the collocation methodology have brought the two instruments closer to a seamless pan-spectral sensor that, in theory, could be used for joint retrievals. Better estimates of the a priori cloud structure from CloudSat, CALIPSO, and other satellite platforms will help improve the ice cloud property retrievals and may improve some of the thermodynamic phase estimates. The retrieval will benefit from improvements in other information, including prior covariances in the geophysical phase space that may depend strongly on cloud regime.

\section{Appendix A}

\begin{tabular}{|c|c|}
\hline Acronym & Meaning \\
\hline AIRS & Atmospheric Infrared Sounder \\
\hline AMSR-E & $\begin{array}{l}\text { Advanced Microwave Scanning Ra- } \\
\text { diometer - Earth Observing System }\end{array}$ \\
\hline AMSU & Advanced Microwave Sounding Unit \\
\hline ARM & $\begin{array}{l}\text { Atmospheric Radiation Measurement } \\
\text { program }\end{array}$ \\
\hline AVHRR & $\begin{array}{l}\text { Advanced Very High Resolution Ra- } \\
\text { diometer }\end{array}$ \\
\hline CALIOP & $\begin{array}{l}\text { Cloud-Aerosol LIdar with Orthogonal } \\
\text { Polarization }\end{array}$ \\
\hline CAM3/CAM5 & $\begin{array}{l}\text { NCAR Community Atmospheric } \\
\text { Model (CAM) version } 3 \text { or } 5\end{array}$ \\
\hline CMIP3/CMIP5 & $\begin{array}{l}\text { Coupled Model Intercomparison } \\
\text { Project Phase } 3 \text { or } 5\end{array}$ \\
\hline CrIS & Cross-track Infrared Sounder \\
\hline D4S & $\begin{array}{l}\text { Delta-four-stream approximation for } \\
\text { radiative transfer }\end{array}$ \\
\hline $\mathrm{ECF}$ & Effective cloud fraction \\
\hline ECHAM5 & $\begin{array}{l}\text { Max Planck Institute for Meteorology } \\
\text { atmospheric general circulation model }\end{array}$ \\
\hline EUMETSAT & $\begin{array}{l}\text { European Organisation for the Ex- } \\
\text { ploitation of Meteorological Satellites }\end{array}$ \\
\hline FOR & $\begin{array}{l}\text { Field of regard }(3 \times 3 \text { AIRS FOVs } \\
\text { coregistered to AMSU FOV) }\end{array}$ \\
\hline FOV & Field of view (AIRS footprint) \\
\hline
\end{tabular}




\begin{tabular}{|c|c|}
\hline HIRS & $\begin{array}{l}\text { High-resolution Infrared Radiation } \\
\text { Sounder }\end{array}$ \\
\hline IASI & $\begin{array}{l}\text { Infrared Atmospheric Sounding Inter- } \\
\text { ferometer }\end{array}$ \\
\hline IPCC AR4 & $\begin{array}{l}\text { Intergovernmental Panel on Climate } \\
\text { Change Fourth Assessment Report }\end{array}$ \\
\hline ISCCP & $\begin{array}{l}\text { International Satellite Cloud Climatol- } \\
\text { ogy Project }\end{array}$ \\
\hline JPSS & Joint Polar Satellite System \\
\hline L2 & $\begin{array}{l}\text { Level } 2 \text { satellite data (retrieved prod- } \\
\text { ucts at FOV scale) }\end{array}$ \\
\hline L3 & $\begin{array}{l}\text { Level } 3 \text { satellite data (gridded FOV } \\
\text { scale data for various time/space aver- } \\
\text { aging) }\end{array}$ \\
\hline LBLRTM & $\begin{array}{l}\text { Line-By-Line Radiative Transfer } \\
\text { Model }\end{array}$ \\
\hline MMF & Multiscale Modeling Framework \\
\hline MODIS & $\begin{array}{l}\text { Moderate Resolution Imaging Spectro- } \\
\text { radiometer }\end{array}$ \\
\hline NASA & $\begin{array}{l}\text { National Aeronautics and Space Ad- } \\
\text { ministration }\end{array}$ \\
\hline NICAM & $\begin{array}{l}\text { Nonhydrostatic ICosahedral Atmo- } \\
\text { spheric Model }\end{array}$ \\
\hline NOAA & $\begin{array}{l}\text { National Oceanic and Atmospheric Ad- } \\
\text { ministration }\end{array}$ \\
\hline QC & Quality control flag \\
\hline SARTA & $\begin{array}{l}\text { Stand-Alone AIRS Radiative Transfer } \\
\text { Algorithm }\end{array}$ \\
\hline Suomi NPP & $\begin{array}{l}\text { Suomi National Polar-orbiting Partner- } \\
\text { ship }\end{array}$ \\
\hline TES & Tropospheric Emission Spectrometer \\
\hline TRMM & Tropical Rainfall Measuring Mission \\
\hline TTL & Tropical tropopause layer \\
\hline UKMO & $\begin{array}{l}\text { United Kingdom Meteorological Of- } \\
\text { fice }\end{array}$ \\
\hline
\end{tabular}

\section{Appendix B}

Below is a simplified overview of cloud-clearing steps and effective cloud fraction/cloud top pressure retrievals.

The AIRS retrieval is a cloud-clearing retrieval in which all parameters except clouds are retrieved from the "clear" radiances produced by the cloud-clearing process (Susskind et al., 2003). Cloud-clearing selects the linear combination of the nine sets of observed radiances that best matches radiances calculated from the current estimate of the physical state, but without clouds, thus representing radiances from the clear portion of the field of regard (FOR). Once determined, this same linear combination is applied to all channels except those above the clouds.

The clouds are fit to the signal that is the observed radiances minus the calculated radiances from the current estimate of the clear state (Susskind et al., 2006). This is done in an iterative manner with the following steps:

1. Generate first guess of clear state from MIT stochastic cloud-clearing and neural network solution, supplemented by climatologies for trace gases, upper atmosphere temperature and water, and surface emissivity.
2. Perform a microwave-only temperature and water vapor retrieval to adjust the first guess to best match observed microwave radiances.

3. First cloud solution on AMSU FOR, starting from an arbitrary cloud state and minimizing (two cloud top pressures and two effective cloud fractions per AMSU FOR).

4. First cloud-clearing solution.

5. Minor adjustments to geophysical state.

6. Second cloud solution on AMSU FOR, starting from step (3) cloud state (two cloud top pressures and two effective cloud fractions per AMSU FOR).

7. Second cloud-clearing solution.

8. Physical retrieval updating reflectivity, surface temperature and shortwave emissivity, the temperature and water vapor profiles, longwave emissivity, and the ozone profile, in that order.

9. Third cloud solution, starting from step (6) cloud state. This one fixes the pressure on the AMSU scale but has separate cloud fractions on the AIRS scale ( 2 cloud top pressures and 18 effective cloud fractions per AMSU FOR).

10. Third cloud-clearing solution.

11. Physical retrieval updating surface temperature and shortwave emissivity, the temperature profile, longwave emissivity, carbon monoxide profile, and methane profile, in that order.

12. Final cloud solution, starting from the step (9) cloud state, solving for both pressure and cloud fraction on the AIRS FOV (18 cloud top pressures and 18 effective cloud fractions per AMSU FOR).

13. Final cloud-clearing and OLR calculation for output.

14. Cloud thermodynamic phase discussed in Sect. 3.1 and ice cloud optical thickness and effective diameter cloud retrieval discussed in Sect. 3.2. 


\section{Appendix C}

Table C1. A list of the AIRS channels used in the retrieval (out of a total of 2378). The noise-equivalent delta temperature (NEdT) is reported in Kelvin for a scene $T_{\mathrm{b}}$ of $250 \mathrm{~K}$. The center of the channel spectral response function (SRF) and the full width at half maximum (FWHM) of the SRF are both reported in wave numbers $\left(\mathrm{cm}^{-1}\right)$. These data are taken from the AIRS channel properties file L2.chan_prop.2012.07.01.v9.5.3.anc, which is available at http://disc.sci.gsfc.nasa.gov/AIRS/documentation/v6_docs.

\begin{tabular}{|c|c|c|c|c|c|c|c|c|c|}
\hline $\begin{array}{l}\text { Ret } \\
\text { Chan \# }\end{array}$ & $\begin{array}{l}\text { AIRS } \\
\text { Chan \# }\end{array}$ & $\begin{array}{l}\text { SRF Center } \\
\text { Freq }\end{array}$ & $\mathrm{NeDT}$ & $\begin{array}{l}\text { SRF } \\
\text { FWHM }\end{array}$ & $\begin{array}{l}\text { Ret } \\
\text { Chan \# }\end{array}$ & $\begin{array}{l}\text { AIRS } \\
\text { Chan \# }\end{array}$ & $\begin{array}{l}\text { SRF Center } \\
\text { Freq }\end{array}$ & $\mathrm{NeDT}$ & $\begin{array}{l}\text { SRF } \\
\text { FWHM }\end{array}$ \\
\hline 1 & 150 & 692.76 & 0.360 & 0.480 & 31 & 730 & 890.41 & 0.142 & 0.623 \\
\hline 2 & 186 & 702.74 & 0.289 & 0.495 & 32 & 757 & 899.62 & 0.128 & 0.635 \\
\hline 3 & 204 & 707.85 & 0.261 & 0.503 & 33 & 764 & 902.04 & 0.193 & 0.638 \\
\hline 4 & 221 & 712.74 & 0.256 & 0.510 & 34 & 799 & 921.64 & 0.161 & 0.667 \\
\hline 5 & 239 & 717.99 & 0.237 & 0.518 & 35 & 807 & 924.56 & 0.183 & 0.671 \\
\hline 6 & 244 & 719.47 & 0.259 & 0.520 & 36 & 812 & 926.39 & 0.133 & 0.674 \\
\hline 7 & 256 & 723.03 & 0.240 & 0.526 & 37 & 819 & 928.96 & 0.101 & 0.678 \\
\hline 8 & 295 & 734.15 & 0.364 & 0.558 & 38 & 824 & 930.81 & 0.149 & 0.681 \\
\hline 9 & 338 & 747.60 & 0.359 & 0.580 & 39 & 833 & 934.16 & 0.145 & 0.686 \\
\hline 10 & 369 & 757.61 & 0.224 & 0.595 & 40 & 839 & 936.41 & 0.188 & 0.689 \\
\hline 11 & 472 & 800.01 & 0.418 & 0.667 & 41 & 844 & 938.29 & 0.148 & 0.692 \\
\hline 12 & 478 & 802.19 & 0.269 & 0.671 & 42 & 848 & 939.79 & 0.137 & 0.695 \\
\hline 13 & 482 & 803.65 & 0.302 & 0.674 & 43 & 853 & 941.69 & 0.123 & 0.698 \\
\hline 14 & 503 & 811.41 & 0.283 & 0.687 & 44 & 860 & 944.35 & 0.117 & 0.702 \\
\hline 15 & 510 & 814.03 & 0.415 & 0.692 & 45 & 869 & 947.80 & 0.141 & 0.707 \\
\hline 16 & 516 & 816.29 & 0.514 & 0.696 & 46 & 873 & 949.34 & 0.147 & 0.709 \\
\hline 17 & 521 & 818.18 & 0.253 & 0.699 & 47 & 882 & 952.83 & 0.155 & 0.715 \\
\hline 18 & 530 & 821.60 & 0.384 & 0.705 & 48 & 897 & 958.69 & 0.137 & 0.724 \\
\hline 19 & 541 & 825.82 & 0.315 & 0.713 & 49 & 908 & 963.04 & 0.120 & 0.730 \\
\hline 20 & 549 & 828.91 & 0.431 & 0.718 & 50 & 914 & 965.43 & 0.121 & 0.734 \\
\hline 21 & 553 & 830.47 & 0.304 & 0.721 & 51 & 1181 & 1093.94 & 0.146 & 0.968 \\
\hline 22 & 565 & 835.17 & 0.397 & 0.729 & 52 & 1195 & 1101.11 & 0.612 & 0.981 \\
\hline 23 & 577 & 839.92 & 0.313 & 0.737 & 53 & 1200 & 1103.69 & 0.164 & 0.985 \\
\hline 24 & 585 & 843.11 & 0.424 & 0.743 & 54 & 1211 & 1109.40 & 0.233 & 0.996 \\
\hline 25 & 653 & 865.21 & 0.217 & 0.590 & 55 & 1218 & 1113.07 & 0.167 & 1.003 \\
\hline 26 & 667 & 869.68 & 0.209 & 0.596 & 56 & 1223 & 1115.70 & 0.249 & 1.007 \\
\hline 27 & 687 & 876.15 & 0.280 & 0.604 & 57 & 1235 & 1122.06 & 0.338 & 1.019 \\
\hline 28 & 695 & 878.77 & 0.179 & 0.608 & 58 & 1247 & 1128.50 & 0.210 & 1.031 \\
\hline 29 & 711 & 884.05 & 0.208 & 0.614 & 59 & 1257 & 1133.91 & 0.249 & 1.041 \\
\hline 30 & 722 & 887.72 & 0.141 & 0.619 & & & & & \\
\hline
\end{tabular}

Acknowledgements. The research described in this paper was carried out at the Jet Propulsion Laboratory (JPL), California Institute of Technology, under a contract with the National Aeronautics and Space Administration. The authors are especially grateful to $\mathrm{H}$. Jin for his work on cloud thermodynamic phase while pursuing his Ph.D at Texas A\&M University. B. H. Kahn, F. W. Irion, V. T. Dang, and E. M. Manning were supported by the AIRS Project at JPL. B. H. Kahn and F. W. Irion were partially supported by NASA award NNX08AI09G at the outset of this effort. C. M. Naud was supported by NASA award NNX11AH22G. D. Lubin was supported by NASA award NNX08AF79G. The AIRS v5 and v6 data sets were processed by and obtained from the Goddard Earth Services Data and Information Services Center (http://daac.gsfc.nasa.gov/) and the AIRS Project Science and Computing Facility at JPL. CloudSat data were obtained through the CloudSat Data Processing Center (http://www.cloudsat.cira.colostate.edu/). CALIPSO data were obtained through the Atmospheric Sciences Data Center (ASDC) at the NASA Langley Research Center (http://eosweb.larc.nasa.gov/). The JPL author's copyright for this publication is held by the California Institute of Technology. Government Sponsorship acknowledged.

Edited by: A. Geer

\section{References}

Ackerman, S. A., Holz, R. E., Frey, R., Eloranta, E., Maddux, B. C., and McGill, M.: Cloud detection with MODIS. Part II: Validation, J. Atmos. Ocean. Tech., 25, 1073-1086, 2008.

Antonelli, P., Revercomb, H. E., Stromovsky, L. A., Smith, W. L., Knuteson, R. O., Tobin, D. C., Garcia, R. K., Howell, H. B., Huang, H.-L., and Best, F. A.: A principal component noise fil- 
ter for high resolution infrared measurements, J. Geophys. Res., 109, D23102, doi:10.1029/2004JD004862, 2004.

Aumann, H. H., Chahine, M. T., Gautier, C., Goldberg, M. D., Kalnay, E., McMillin, L. M., Revercomb, H., Rosenkranz, P. W., Smith, W. L., Staelin, D. H., Strow, L. L., and Susskind, J.: AIRS/AMSU/HSB on the Aqua mission: Design, science objectives, data products, and processing systems, IEEE Trans. Geosci. Remote, 41, 253-264, 2003.

Barahona, D., Rodriguez, J., and Nenes, A.: Sensitivity of the global distribution of cirrus ice crystal concentration to heterogeneous freezing. J. Geophys. Res., 115, D23213, doi:10.1029/2010JD014273, 2010.

Baum, B. A., Yang, P, Nasiri, S. L., Heidinger, A. K., Heymsfield, A. J., and Li, J.: Bulk scattering properties for the remote sensing of ice clouds. Part III: High-resolution spectral models from 100 to $3250 \mathrm{~cm}^{-1}$, J. Appl. Meteorol. Climatol., 46, 423-434, 2007.

Bender, F. A. M., Ramanathan, V., and Tselioudis, G.: Changes in extratropical storm track cloudiness 1983-2008: Observational support for a poleward shift, Clim. Dyn., 38, 2037-2053, 2012.

Bengtsson, L., Hodges, K. I., and Roeckner, E.: Storm tracks and climate change. J. Climate, 19, 3518-3543, 2006.

Blackwell, W. J., Pieper, M., and Jairam, L. G.: Neural network estimation of atmospheric profiles using AIRS/IASI/AMSU data in the presence of clouds, Proc of SPIE, 7149, doi:10.1117/12.804841, 2008.

Bodas-Salcedo, A., Williams, K. D., Field, P. R., and Lock, A. P.: The surface downwelling solar radiation surplus over the Southern Ocean in the Met Office model: The role of midlatitude cyclone clouds, J. Climate, 25, 7467-7486, 2012.

Bony, S. and Dufresne, J.-L.: Marine boundary layer clouds at the heart of tropical cloud feedback uncertainties in climate models, Geophys. Res. Lett., 32, L20806, doi:10.1029/2005GL023851, 2005.

Bowman, K. W., Rodgers, C. D., Kulawik, S. S., Worden, J., Sarkission, E., Osterman, G., Stieck, T., Lou, M., Eldering, A., Shephard, M., Worden, H., Lampel, M., Clough, S., Brown, P., Rinsland, C., Gunson, M., and Beer, R.: Tropospheric Emission Spectrometer: Retrieval method and error analysis, IEEE. Trans. Geosci. Remote Sens., 44, 1297-1307, 2006.

Cairns, B.: Diurnal variations of cloud from ISCCP data, Atmos. Res., 37, 133-146, 1995.

Chahine, M. T., Pagano, T. S., Aumann, H. H., Atlas, R., Barnet, C., Blaisdell, J., Chen, L., Divakarla, M., Fetzer, E. J., Goldberg, M., Gautier, C., Granger, S., Hannon, S., Irion, F. W., Kakar, R., Kalnay, E., Lambrigtsen, B. H., Lee, S.-Y., Le Marshall, J., McMillan, W. W., McMillin, L., Smith, W. L., Staelin, D., Strow, L. L., Susskind, J., Tobin, D., Wolf, W., and Zhou, L.: The Atmospheric Infrared Sounder (AIRS): Improving weather forecasting and providing new insights into climate, B. Am. Meteor. Soc., 87, 911-926, doi:10.1175/BAMS-87-7-911, 2006.

Chen, S. S. and Houze, R. A.: Diurnal variation and life-cycle of deep convective systems over the tropical Pacific warm pool, Q. J. Roy. Meteorol. Soc., 123, 357-388, 1997.

Cheng, A., Xu, K.-M., Hu, Y., and Kato, S.: Impact of a cloud thermodynamic phase parameterization based on CALIPSO observations on climate simulation, J. Geophys. Res., 117, D09103, doi:10.1029/2011JD017263, 2012.

Choi, Y.-S., Ho, C.-H., Kim, S.-W., and Lindzen, R. S.: Observational diagnosis of cloud phase in the winter Antarctic atmo- sphere for parameterizations in climate models, Adv. Atmos. Sci., 27, 1233-1245, 2010.

Chylek, P., Robinson, S., Dubey, M. K., King, M. D., Fu, Q., and Clodius, W. B.: Comparison of near-infrared and thermal infrared cloud phase detections, J. Geophys. Res., 111, D20203, doi:10.1029/2006JD007140, 2006.

Clement, A. C., Burgman, R., and Norris, J. R.: Observational and model evidence for positive low-level cloud feedback, Science, 325, 460-464, 2009.

Cooper, S. J., L'Ecuyer, T. S., Gabriel, P., Baran, A. J., and Stephens, G. L.: Performance assessment of a five-channel estimationbased ice cloud retrieval scheme for use over the global oceans, J. Geophys. Res., 112, D04207, doi:10.1029/2006JD007122, 2007.

Curry, J. A. and Ebert, E. E.: Annual cycle of radiation fluxes over the Arctic Ocean: Sensitivity to cloud optical properties, J. Climate, 5, 1267-1280, 1992.

Dai, A.: Precipitation characteristics in eighteen coupled climate models, J. Climate, 19, 4605-4630, 2006.

Dim, J. R., Murakami, H., Nakajima, T. Y., Nordell, B., Heidinger, A. K., and Takamura, T.: The recent state of the climate: Driving components of cloud-type variability, J. Geophys. Res., 116, D11117, doi:10.1029/2010JD014559, 2011.

Eldering, A., Kulawik, S. S., Worden, J., Bowman, K., and Osterman, G.: Implementation of cloud retrievals for TES atmospheric retrievals: 2. Characterization of cloud top pressure and effective optical depth retrievals, J. Geophys. Res., 113, D16S37, doi:10.1029/2007JD008858, 2008.

Evan, A. T., Heidinger, A. K., and Vimont, D. J.: Arguments against a physical long-term trend in global ISCCP cloud amounts, Geophys. Res. Lett., 34, L04701, doi:10.1029/2006GL028083, 2007.

Fasullo, J. T. and Trenberth, K. E.: A less cloudy future: The role of subtropical subsidence in climate sensitivity. Science, 338, 792794, doi:10.1126/science.1227465, 2012.

Field, P. R. and Wood, R.: Precipitation and cloud structure in midlatitude cyclones, J. Climate, 20, 233-254, 2007.

Field, P. R., Gettelman, A., Neale, R. B., Wood, R., Rasch, P. J., and Morrison, H.: Midlatitude cyclone compositing to constrain climate model behavior using satellite observations, J. Climate, 21, 5887-5903, 2008.

Foster, M. and Heidinger, A.: PATMOS-x: Results from a diurnallycorrected thirty-year satellite cloud climatology, J. Climate, 26, 414-425, doi:10.1175/JCLI-D-11-00666.1, 2013.

Gettelman, A., Liu, X., Ghan, S. J., Morrison, H., Park, S., Conley, A. J., Klein, S. A., Boyle, J., Mitchell, D. L., and Li, J.-L. F.: Global simulations of ice nucleation and ice supersaturation with an improved cloud scheme in the Community Atmosphere Model, J. Geophys. Res., 115, D18216, doi:10.1029/2009JD013797, 2010.

Gettelman, A., Liu, X., Barahona, D., Lohmann, U., and Chen, C.: Climate impacts of ice nucleation, J. Geophys. Res., 117, D20201, doi:10.1029/2012JD017950, 2012.

Gordon, N. D. and Norris, J. R.: Cluster analysis of midlatitude oceanic cloud regimes: mean properties and temperature sensitivity, Atmos. Chem. Phys., 10, 6435-6459, doi:10.5194/acp-106435-2010, 2010.

Guignard, A., Stubenrauch, C. J., Baran, A. J., and Armante, R.: Bulk microphysical properties of semi-transparent cirrus from AIRS: a six year global climatology and statistical analysis in synergy with geometrical profiling data from CloudSat- 
CALIPSO, Atmos. Chem. Phys., 12, 503-525, doi:10.5194/acp12-503-2012, 2012.

Heidinger, A. K. and Pavolonis, M. J.: Gazing at cirrus clouds for 25 years through a split-window. Part I: Methodology, J. Appl. Meteorol. Climatol., 48, 1100-1116, 2009.

Hendricks, J., Kärcher, B., and Lohmann, U.: Effects of ice nuclei on cirrus clouds in a global climate model, J. Geophys. Res., 116, D18206, doi:10.1029/2010JD015302, 2011.

Hilton, F., Armante, R., August, T., Barnet, C., Bouchard, A., Canay-Peyret, C., Capelle, V., Clarisse, L., Clerbaux, C., Coheur, P.-F., Collard, A., Crevoisier, C., Dufour, G., Edwards, D., Faijan, F., Fourrie, N., Gambacorta, A., Goldberg, M., Guidard, V., Hurtmans, D., Illingworth, S., Jacquinet-Hasson, N., Kerzenmacher, T., Klaes, D., Lavanant, L., Masiello, G., Matricardi, M., McNally, A., Newman, S., Pavelin, E., Payan, S., Pequignot, E., Peyridieu, S., Phulpin, T., Remedios, J., Schlussel, P., Serio, C., Strow, L., Stubenrauch, C., Taylor, J., Tobin, D., Wolf, W., and Zhou, D.: Hyperspectral Earth observation from IASI, B. Am. Meteor. Soc., 93, 347-370, 2012.

Hogan, R. J., Behera, M. D., O'Connor, E. J., and Illingworth, A. J.: Estimate of the global distribution of stratiform supercooled liquid water clouds using the LITE lidar, Geophys. Res. Lett., 31, L05106, doi:10.1029/2003GL018977, 2004.

Hong, G., Yang, P., Gao, B.-C., Baum, B. A., Hu, Y. X., King, M. D., and Platnick, S.: High cloud properties from three years of MODIS Terra and Aqua Collection-4 data over the tropics, J. Appl. Meteor. Climatol., 46, 1840-1856, 2007.

Hu, Y., Winker, D., Vaughan, M., Liu, B., Omar, A., Trepte, C., Flittner, D., Yang, P., Nasiri, S. L., Baum, B. A., Sun, W., Liu, Z., Wang, Z., Young, S., Stamnes, K., Huang, J., Kuehn, R., and Holz, R.: CALIPSO/CALIOP cloud phase discrimination algorithm, J. Atmos. Ocean. Tech., 26, 2293-2309, 2009.

Hu, Y., Rodier, S., Xu, K., Sun, W., Huang, J., Lin, B., Zhai, P., and Josset, D.: Occurrence, liquid water content, and fraction of supercooled water clouds from combined CALIOP/IIR/MODIS measurements, J. Geophys. Res., 115, D00H34, doi:10.1029/2009JD012384, 2010.

Huang, H.-L. and Antonelli, P.: Application of principal component analysis to high- resolution infrared measurement compression and retrieval, J. Appl. Meteor., 40, 365-388, 2001.

Hulley, G. C. and Hook, S. J.: A radiance-based method for estimating uncertainties in the Atmospheric Infrared Sounder (AIRS) land surface temperature product, J. Geophys. Res., 117, D20117, doi:10.1029/2012JD018102, 2012.

Hulley, G. C., Hook, S. J., Manning, E., Lee, S.-Y., and Fetzer, E.: Validation of the Atmospheric Infrared Sounder (AIRS) Version 5 Land Surface Emissivity Product over the Namib and Kalahari Deserts, J. Geophys. Res., 114, D19104, doi:10.1029/2009JD012351, 2009.

Jin, H.: Satellite remote sensing of mid-level clouds, Ph.D. Dissertation, Texas A\&M University, 151 pp., 2012.

Jin, H. and Nasiri, S. L.: Evaluation of AIRS cloud thermodynamic phase determination with CALIPSO, J. Appl. Meteor. Climatol., doi:10.1175/JAMC-D-13-0137.1, in press, 2013.

Johanson, C. M. and Fu, Q.: Hadley cell widening: Model simulations versus observations, J. Climate, 22, 2713-2725, 2009.

Joos, H., Spichtinger, P., and Lohmann, U.: Influence of a future climate on the microphysical and optical properties of orographic cirrus clouds in ECHAM5, J. Geophys. Res., 115, D19129, doi:10.1029/2010JD013824, 2010.

Kahn, B. H., Eldering, A., Braverman, A. J., Fetzer, E. J., Jiang, J. H., Fishbein, E., and Wu, D. L.: Toward the characterization of upper tropospheric clouds using Atmospheric Infrared Sounder and Microwave Limb Sounder observations, J. Geophys. Res., 112, D05202, doi:10.1029/2006JD007336, 2007.

Kahn, B. H., Chahine, M. T., Stephens, G. L., Mace, G. G., Marchand, R. T., Wang, Z., Barnet, C. D., Eldering, A., Holz, R. E., Kuehn, R. E., and Vane, D. G.: Cloud type comparisons of AIRS, CloudSat, and CALIPSO cloud height and amount, Atmos. Chem. Phys., 8, 1231-1248, doi:10.5194/acp-8-1231-2008, 2008a.

Kahn, B. H., Liang, C. K., Eldering, A., Gettelman, A., Yue, Q., and Liou, K. N.: Tropical thin cirrus and relative humidity observed by the Atmospheric Infrared Sounder, Atmos. Chem. Phys., 8, 1501-1518, doi:10.5194/acp-8-1501-2008, 2008b.

Kahn, B. H., Nasiri, S. L., Schreier, M. M., and Baum, B. A.: Impacts of sub-pixel cloud heterogeneity on infrared thermodynamic phase assessment, J. Geophys. Res., 116, D20201, doi:10.1029/2011JD015774, 2011.

Kay, J. E., Hillman, B. R., Klein, S. A., Zhang, Y., Medeiros, B., Pincus, R., Gettelman, A., Eaton, B., Boyle, J., Marchand, R., and Ackerman, T. P.: Exposing global cloud biases in the Community Atmosphere Model (CAM) using satellite observations and their corresponding instrument simulators, J. Climate, 25, 5190-5207, 2012.

Klein, S. A. and Jakob, C.: Validation and sensitivities of frontal clouds simulated by the ECMWF model, Mon. Weather Rev., 127, 2514-2531, 1999.

Klein, S. A., McCoy, R. B., Morrison, H., Ackerman, A. S., Avramov, A., de Boer, G., Chen, M., Cole, J. N. S., Del Genio, A. D., Falk, M., Foster, M. J., Fridlind, A., Golaz, J.-C., Hashino, T., Harrington, J. Y., Hoose, C., Khairoutdinov, M., Larson, V. E., Liu, X., Luo, Y., McFarquhar, G. M., Menon, S., Neggers, R. A. J., Park, S., Poellot, M. R., Schmidt, J. M., Sednev, I., Shipway, B. J., Shupe, M. D., Spangenberg, D. A., Sud, Y. C., Turner, D. D., Veron, D. E., van Salzen, K., Walker, G. K., Wang, Z., Wolf, A. B., Xie, S., Xu, K.-M., Yang, F., and Zhang, G.: Intercomparison of model simulations of mixed-phase clouds observed during the ARM Mixed-Phase Arctic Cloud Experiment. I: Single-layer cloud, Q. J. Roy. Meteor. Soc., 135, 979-1002, 2009.

Kulawik, S. S., Worden, J., Eldering, A., Bowman, K., Gunson, M., Osterman, G. B., Zhang, L., Clough, S. A., Shephard, M. W., and Beer, R.: Implementation of cloud retrievals for Tropospheric Emission Spectrometer (TES) atmospheric retrievals: part 1. Description and characterization of errors on trace gas retrievals, J. Geophys. Res., 111, D24204, doi:10.1029/2005JD006733, 2006.

Lau, N.-C. and Crane, M. W.: A satellite view of the synoptic-scale organization of cloud properties in midlatitude and tropical circulation systems, Mon. Weather Rev., 123, 1984-2006, 1995.

Liou, K.-N.: Influence of cirrus clouds on weather and climate processes: A global perspective, Mon. Weather Rev., 114, 11671199, 1986.

Liu, X., Smith, W. L., Zhou, D. K., and Larar, A. M.: A principal component-based radiative transfer forward model (PCRTM) for hyperspectral measurements, Proc. SPIE 5655, Multispectral and Hyperspectral Remote Sensing Instruments and Applications II, 96, doi:10.1117/12.578996, 2005. 
Liu, X., Shi, X., Zhang, K., Jensen, E. J., Gettelman, A., Barahona, D., Nenes, A., and Lawson, P.: Sensitivity studies of dust ice nuclei effect on cirrus clouds with the Community Atmosphere Model CAM5, Atmos. Chem. Phys., 12, 12061-12079, doi:10.5194/acp-12-12061-2012, 2012.

Medeiros, B., Stevens, B., Held, I. M., Zhao, M., Williamson, D. L., Olson, J. G., and Bretherton, C. S.: Aquaplanets, climate sensitivity, and low clouds, J. Climate, 21, 4974-4991, 2008.

Meyer, K., Yang, P., and Gao, B.-C.: Tropical ice cloud optical depth, ice water path, and frequency fieldsfrom the MODIS level3 data, Atmos. Res., 85, 171-182, 2007.

Nasiri, S. L. and Kahn, B. H.: Limitations of bi-spectral infrared cloud phase determination and potential for improvement, J. Appl. Meteorol. Clim., 47, 2895-2910, 2008.

Nasiri, S. L., Dang, V. T., Kahn, B. H., Fetzer, E. J., Manning, E. M., Schreier, M. M., and Frey, R. A.: Comparing MODIS and AIRS infrared-based cloud retrievals, J. Appl. Meteor. Clim., 50, 1057-1072, doi:10.1175/2010JAMC2603.1, 2011.

Naud, C. M., Del Genio, A. D., and Bauer, M.: Observational constraints on the cloud thermodynamic phase in midlatitude storms, J. Climate, 19, 5273-5288, 2006.

Naud, C. M., Del Genio, A. D., Bauer, M., and Kovari, W.: Cloud vertical distribution across warm and cold fronts in CloudSatCALIPSO data and a general circulation model, J. Climate, 23, 3397-3415, 2010.

Naud, C. M., Posselt, D. J., and van den Heever, S. C.: Observational analysis of cloud and precipitation in midlatitude cyclones: Northern versus southern hemisphere warm fronts, J. Climate, 25, 5135-5151, 2012.

Neale, R. and Slingo, J.: The maritime continent and its role in the global climate: A GCM study, J. Climate, 16, 834-848, 2003.

Nesbitt, S. W. and Zipser, E. J.: The diurnal cycle of rainfall and convective intensity according to the three years of TRMM measurements, J. Climate, 16, 1456-1475, 2003.

Norris, J. R. and Slingo, A.: Trends in observed cloudiness and Earth's radiation budget: What do we not know and what do we need to know?, in: Clouds in the Perturbed Climate System, edited by: Heintzenberg, J. and Charlson, R. J., The MIT Press, 17-36, 2009.

Olsen, E. T., Fetzer, E., Hulley, G., Lambrigtsen, B., Manning, E., Warner, J., Wei, Z., and Blackwell, W.: AIRS/AMSU/HSB Version 6 changes from Version 5. JPL Document V1.0, http: //disc.gsfc.nasa.gov/, 27 pp., 2013.

Ou, S.-C., Kahn, B. H., Liou, K. N., Takano, Y., Schreier, M. M., and Yue, Q.: Retrieval of cirrus cloud properties from the Atmospheric Infrared Sounder: The k-coefficient approach combined with SARTA plus delta-four stream approximation, IEEE Trans. Geosci. Remote, 51, 1010-1024, 2013.

Pincus, R., Platnick, S., Ackerman, S. A., Hemler, R. S., and Hofmann, R. J. P.: Reconciling simulated and observed views of clouds: MODIS, ISCCP, and the limits of instrument simulators, J. Climate, 25, 4699-4720, 2012.

Platnick, S., King, M. D., Ackerman, S. A., Menzel, W. P., Baum, B. A., and Frey, R. A.: The MODIS cloud products: Algorithms and examples from Terra, IEEE Trans. Geosci. Remote, 41, 459-473, 2003.

Posselt, D., L'Ecuyer, T. S., and Stephens, G. L.: Exploring the error characteristics of thin ice cloud property retrievals using a
Markov chain Monte Carlo algorithm, J. Geophys. Res., 113, D24206, doi:10.1029/2008JD010832, 2008.

Pritchard, M. S. and Somerville, R. C. J.: Assessing the diurnal cycle of precipitation in a multi-scale climate model, JAMES, 1, 12, doi:10.3894/james.2009.1.12, 2009.

Protat, A., Delanoë, J., May, P. T., Haynes, J., Jakob, C., O’Connor, E., Pope, M., and Wheeler, M. C.: The variability of tropical ice cloud properties as a function of the large-scale context from ground-based radar-lidar observations over Darwin, Australia, Atmos. Chem. Phys., 11, 8363-8384, doi:10.5194/acp-11-83632011, 2011.

Qian, J. H.: Why precipitation is mostly concentrated over islands in the Maritime Continent, J. Atmos. Sci., 65, 1428-1441, doi:10.1175/2007jas2422.1, 2008

Quaas, J.: Evaluating the "critical relative humidity" as a measure of subgrid-scale variability of humidity in general circulation model cloud cover parameterizations using satellite data, J. Geophys. Res., 117, D09208, doi:10.1029/2012JD017495, 2012.

Riedi, J., Marchant, B., Platnick, S., Baum, B. A., Thieuleux, F., Oudard, C., Parol, F., Nicolas, J.-M., and Dubuisson, P.: Cloud thermodynamic phase inferred from merged POLDER and MODIS data, Atmos. Chem. Phys., 10, 11851-11865, doi:10.5194/acp-10-11851-2010, 2010.

Rodgers, C. D.: Inverse Methods for Atmospheric Sounding: Theory and Practice, World Scientific, 238 pp., 2000.

Rossow, W. B., and Schiffer, R. A.: Advances in understanding clouds from ISCCP. Bull. Amer. Met. Soc., 80, 2261-2287, 1999.

Rossow, W. B., Mosher, F., Kinsella, E., Arking, A., Desbois, M., Harrison, E., Minnis, P., Ruprecht, E., Seze, G., Simmer, C, and Smith, E.: ISCCP cloud algorithm intercomparison, J. Clim. Appl. Meteor., 24, 877-903, 1985.

Rossow, W. B., Tselioudis, G., Polak, A., and Jakob, C.: Tropical climate described as a distribution of weather states indicated by distinct mesoscale cloud property mixtures, Geophys. Res. Lett., 32, L21812, doi:10.1029/2005GL024584, 2005.

Sassen, K., Wang, Z., and Liu, D.: Global distribution of cirrus clouds from CloudSat/Cloud-Aerosol Lidar and Infrared Pathfinder Satellite Observations (CALIPSO) measurements, J. Geophys. Res., 113, D00A12, doi:10.1029/2008JD009972, 2008.

Sassen, K., Wang, Z., and Liu, D.: Cirrus clouds and deep convection in the tropics: Insights from CALIPSO and CloudSat, J. Geophys. Res., 114, D00H06, doi:10.1029/2009JD011916, 2009.

Sato, T., Miura, H., Satoh, M., Takayabu, Y. N., and Wang, Y.: Diurnal cycle of precipitation in the tropics simulated in a global cloud-resolving model, J. Climate, 22, 4809-4826, 2009.

Schneider, T., O'Gorman, P. A., and Levine, X. J.: Water vapor and the dynamics of climate changes, Rev. Geophys., 48, RG3001, doi:10.1029/2009RG000302, 2010.

Seemann, S. W., Borbas, E. E., Knuteson, R. O., Stephenson, G. R., and Huang, H.-L.: Development of a Global Infrared Land Surface Emissivity Database for Application to Clear Sky Sounding Retrievals from Multispectral Satellite Radiance Measurements, J. Appl. Meteor. Climatol., 47, 108-123, 2008.

Smith Sr., W. L., Weisz, E., Kireev, S. V., Zhou, D. K., Li, Z., and Borbas, E.: Dual- regression retrieval algorithm for real-time processing of satellite ultraspectral radiances, J. Appl. Meteor. Climatol., 51, 1455-1476, 2012. 
Stephens, G. L., Vane, D. G., Tanelli, S., Im, E., Durden, S., Rokey, M., Reinke, D., Partain, P., Mace, G. G., Austin, R., L'Ecuyer, T., Haynes, J., Lebsock, M., Suzuki, K., Waliser, D., Wu, D., Kay, J., Gettelman, A., Wang, Z., and Marchand, R.: CloudSat mission: Performance and early science after the first year of operation, J. Geophys. Res., 113, D00A18, doi:10.1029/2008JD009982, 2008.

Storelvmo, T., Kristjansson, J. E., and Lohamnn, U.: Aerosol influence on mixed-phase clouds in CAM-Oslo, J. Atmos. Sci., 65, 3214-3230, 2008.

Strow, L. L., Hannon, S. E., De-Souza Machado, S., Motteler, H. E., and Tobin, D. C.: Validation of the Atmospheric Infrared Sounder radiative transfer algorithm, J. Geophys. Res., 111, D09S06, doi:10.1029/2005JD006146, 2006.

Stubenrauch, C. J., Eddounia, F., and Rädel, G.: Correlations between microphysical properties of large-scale semi-transparent cirrus and the state of the atmosphere, Atmos. Res., 72, 403-423, 2004

Stubenrauch, C. J., Chédin, A., Rädel, G., Scott, N. A., and Serrar, S.: Cloud properties and their seasonal and diurnal variability from TOVS Path-B, J. Climate, 19, 5531-5553, 2006.

Stubenrauch, C. J., Cros, S., Guignard, A., and Lamquin, N.: A 6-year global cloud climatology from the Atmospheric InfraRed Sounder AIRS and a statistical analysis in synergy with CALIPSO and CloudSat, Atmos. Chem. Phys., 10, 7197-7214, doi:10.5194/acp-10-7197-2010, 2010.

Stubenrauch, C. J., Rossow, W., Kinne, S., Ackerman, S., Cesana, G., Chepfer, H., Di Girolamo, L., Getzewich, B., Guignard, A., Heidinger, A., Maddux, B. C., Menzel, W. P., Minnis, P., Pearl, C., Platnick, S., Poulsen, C., Riedi, J., Sun-Mack, S., Walther, A., Winker, D., Zeng, S., and Zhao, G.: Assessment of global cloud data sets from satellites: Project and database initiated by the GEWEX radiation panel, B. Am. Meteor. Soc., 94, 10311039, doi:10.1175/BAMS-D-12-00117, 2013.

Susskind, J. and Blaisdell, J.: Improved surface parameter retrievals using AIRS/AMSU data, Proc. SPIE Int. Soc. Opt. Eng., 6966, 696610, doi:10.1117/12.774759, 2008.

Susskind, J., Barnet, C. D., and Blaisdell, J. M.: Retrieval of atmospheric and surface parameters from AIRS/AMSU/HSB data in the presence of clouds, IEEE Trans. Geosci. Remote, 41, 390409, 2003

Susskind, J., Barnet, C., Blaisdell, J., Iredell, L., Keita, F., Kouvaris, L., Molnar, G., and Chahine, M.: Accuracy of geophysical parameters derived from Atmospheric Infrared Sounder/Advanced Microwave Sounding Unit as a function of fractional cloud cover, J. Geophys. Res., 111, D09S17, doi:10.1029/2005jd006272, 2006.

Taylor, P. C.: Tropical outgoing longwave radiation and longwave cloud forcing diurnal cycles from CERES, J. Atmos. Sci., 69, 3652-3669, doi:10.1175/jas-d-12-088.1, 2012

Tian, B., Soden, B. J., and Wu, X.: Diurnal cycle of convection, clouds, and water vapor in the tropical upper troposphere: Satellites versus a general circulation model, J. Geophys. Res., 109, D10101, doi:10.1029/2003JD004117, 2004.

Tian, B., Waliser, D. E., and Fetzer, E. J.: Modulation of the diurnal cycle of tropical deep convective clouds by the MJO, Geophys. Res. Lett., 33, L20704, doi:10.1029/2006g1027752, 2006.
Trenberth, K. E. and Fasullo, J. T.: Simulation of present-day and twenty-first-century energy budgets of the Southern Oceans, J. Climate, 23, 440-454, 2010.

Tsushima, Y. Emori, S., Ogura, T., Kimoto, M., Webb, M. J., Williams, K. D., Ringer, M. A., Soden, B. J., Li, B., and Andronova, N.: Importance of the mixed-phase cloud distribution in the control climate for assessing the response of clouds to carbon dioxide increase: a multi-model study, Climate Dyn., 27, 113126, 2006.

Wang, C., Yang, P., Platnick, S., Heidinger, A., Baum, B., Greenwald, T., Zhang, Z., and Holz, R.: Retrieval of ice cloud properties from AIRS and MODIS observations based on a fast highspectral-resolution radiative transfer model, J. Appl. Meteor. Climatol., 52, 710-726, doi:10.1175/JAMC-D-12-020.1, 2013.

Wang, M. and Penner, J. E.: Cirrus clouds in a global climate model with a statistical cirrus cloud scheme, Atmos. Chem. Phys., 10, 5449-5474, doi:10.5194/acp-10-5449-2010, 2010

Wei, H., Yang, P., Li, J., Baum, B. A., Huang, H. L., Platnick, S., Hu, Y. X., and Strow, L.: Retrieval of semitransparent ice cloud optical thickness from Atmospheric Infrared Sounder (AIRS) measurements, IEEE Trans. Geosci. Remote, 42, 2254-2266, 2004.

Williams, K. D. and Tselioudis, G.: GCM intercomparison of global cloud regimes: present-day evaluation and climate change response, Clim. Dyn., 29, 231-250, 2007.

Winker, D. M., Pelon, J., Coakley, J. A., Ackerman, S. A., Charlson, R. J., Colarco, P. R., Flamant, P., Fu, Q., Hoff, R. M., Kittaka, C., Kubar, T. L., Le Treut, H., McCormick, M. P., Megie, E., Poole, L., Powell, K., Trepte, C., Vaughan, M. A., and Wielicki, B. A.: The CALIPSO mission. A global 3D view of aerosols and clouds, B. Am. Meteor. Soc., 91, 1211-1229, 2010.

Wood, R.: Stratocumulus clouds, Mon. Weather Rev., 140, 2373 2423, 2012.

Wood, R. and Field, P. R.: The distribution of cloud horizontal sizes, J. Climate, 24, 4800-4816, 2011.

Wylie, D., Jackson, D. L., Menzel, W. P., and Bates, J. J.: Trends in global cloud cover in two decades of HIRS observations, J. Climate, 18, 3021-3031, 2005.

Yang, G.-Y. and Slingo, J.: The diurnal cycle in the tropics, Mon. Weather Rev., 129, 784-801, 2001.

Yang, P., Zhang, L., Hong, G., Nasiri, S. L., Baum, B. A., Huang, H.-L., King, M. D., and Platnick, S. A.: Differences between Collection 4 and 5 MODIS ice cloud optical/microphysical products and their impact on radiative forcing simulations, IEEE Trans. Geosci. Remote, 45, 2886-2899, 2007.

Yuan, T. and Li, Z.: General macro- and microphysical properties of deep convective clouds as observed by MODIS, J. Climate, 23, 3457-3473, 2010.

Yue, Q. and Liou, K. N.: Cirrus cloud optical and microphysical properties determined from AIRS infrared spectra, Geophys. Res. Lett., 36, L05810, doi:10.1029/2008GL036502, 2009.

Zelinka, M. D., Klein, S. A., and Hartmann, D. L.: Computing and partitioning cloud feedbacks using cloud property histograms. Part II: Attribution to changes in cloud amount, altitude and optical depth, J. Climate, 25, 3736-3754, 2012.

Zhang, M. H., Lin, W. Y., Klein, S. A., Bacmeister, J. T., Bony, S., Cederwall, R. T., Del Genio, A. D., Hack, J. J., Loeb, N. G., Lohmann, U., Minnis, P., Masat, I., Pincus, R., Stier, P., Suarez, M. J., Webb, M. J., Wu, J. B., Xie, S. C., Yao, M.-S., and Zhang, J. H.: Comparing clouds and their seasonal variations in 10 atmo- 
spheric general circulation models with satellite measurements, J. Geophys. Res., 110, D15S02, doi:10.1029/2004JD005021, 2005.
Zhang, Y. Y., Klein, S. A., Liu, C. T., Tian, B., Marchand, R. T., Haynes, J. M., McCoy, R. B., Zhang, Y., and Ackerman, T. P.: On the diurnal cycle of deep convection, high-level cloud, and upper troposphere water vapor in the Multiscale Modeling Framework, J. Geophys. Res., 113, D16105, doi:10.1029/2008jd009905, 2008. 